\title{
The Effect of Universal Design for Learning (UDL) Application on E-learning Acceptance: A Structural Equation Model
}

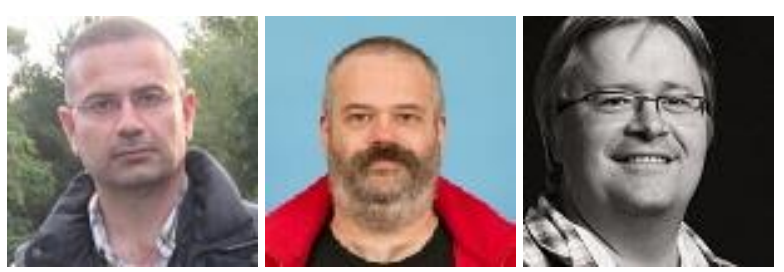

Ahmed Al-Azawei ${ }^{1,2}$, Patrick Parslow ${ }^{1}$, and Karsten Lundqvist ${ }^{3}$

1 University of Reading, Reading, United Kingdom, ${ }^{2}$ University of Babylon, Babel, Iraq, ${ }^{3}$ Victoria University of Wellington, Wellington, New Zealand

\begin{abstract}
Standardising learning content and teaching approaches is not considered to be the best practice in contemporary education. This approach does not differentiate learners based on their individual abilities and preferences. The present research integrates a pedagogical theory Universal Design for Learning (UDL) with an information system (IS) theory Technology Acceptance Model (TAM). It aims to examine the effectiveness of a technology-enhanced traditional web design course on blended elearning acceptance and learner satisfaction in which UDL principles (multiple means of representation, action and expression, and engagement) were implemented. This casts some light on the role of addressing curricula limitations on learner perceptions and e-learning adoption. A mixed research design combining survey and action methods was followed. Overall, 92 undergraduate students took part in the study. The research instrument was validated first. Subsequently, partial least squares-structural equation modelling (PLS-SEM) was applied to identify the path associated among constructs used in the proposed framework. The extended model accounted for $45.4 \%$ and $41.6 \%$ of the variance of perceived satisfaction and behavioural intention respectively. The findings suggest that using educational technologies to address curricula limitations is a bridge to enhancing learner willingness to accept e-learning.
\end{abstract}

Keywords: Universal Design for Learning (UDL), Technology Acceptance Model (TAM), perceived satisfaction, blended learning

\section{Introduction}

Educational institutions around the world have incorporated different learning technologies such as learning management systems (LMSs) in order to support the learning process. The usage of such 
technologies alongside traditional campus-based learning constitutes "blended learning." It has been widely adopted in higher education as a compromise between face to face ( $\left.\mathrm{F}_{2} \mathrm{~F}\right)$ and web-based learning modes. Blended learning represents a possible solution to tackle the issue of learners' differences by addressing their individual needs. However, the traditional application of e-learning follows a "onesize-fits-all” teaching approach (Graf, 2007). According to Rose, Harbour, Johnston, Daley, \& Abarbanell (2006), this approach is no longer addressing learner variety in today's education. Therefore, online or blended e-courses should be designed and utilised in such a way that addresses individual learner needs.

Many learning theories have been proposed to serve the wide variety of student characteristics such as Universal Instructional Design (UID), Universal Design of Instruction (UDI), and Universal Design for Learning (UDL) (Rao, Ok, \& Bryant, 2014). These models were inspired by the Universal Design (UD) framework as applied in architecture (Rose \& Meyer, 2002). Based on the earlier literature, the UDL framework has attracted significant attention by educationalists for tackling limitations in curricula design (Davies, Schelly, \& Spooner, 2012; Kumar \& Wideman, 2014; Rao et al., 2014; Smith \& Harvey, 2014).

In the 1970s, Ronald Mace coined the term Universal Design (UD) in architecture to highlight "the design of products and environments to be usable by all people, to the greatest extent possible, without the need for adaptation or specialized design" (Center for Universal Design, 2015). The Center for Applied Special Technology (CAST) proposed UDL in 2002 as an iteration of UD (Rose \& Meyer, 2002). However, it was revised and updated to introduce UDL 2.0 in 2011. According to CAST (2011, p. 4), UDL is "a framework that addresses the primary barrier to fostering expert learners within instructional environments: inflexible, 'one-size-fits-all' curricula. It is inflexible curricula that raise unintentional barriers to learning." The UDL framework is being used more and more from the beginning to address learner preferences and needs rather than at later stages, which call for adaptation or retrofitting. It consists of three guiding principles, namely, multiple means of representation, expression, and engagement which are associated with recognition, strategic, and affective learning networks respectively. In order to adopt the model, CAST provided the guidelines to assist as a directive framework for education (CAST, 2011). The three principles of the model are:

- Multiple means of representation (MMR): tutors need to present learning content and information by multiple means. This can assist learners to master learning content with less effort.

- Multiple means of action and expression (MMAE): an essential step in the learning process is the way students express their understanding. These approaches should be differentiated according to the learner's individual preferences.

- Multiple means of engagement (MME): in order to engage students, they should be stimulated and motivated in different ways and actions.

It has been shown that UDL application in higher education can promote learner experience in terms of performance, engagement, satisfaction, social presence, learning stress, and learning flexibility (Davies et al., 2012; Hall, Cohen, Vue, \& Ganley, 2015; He, 2014; Kumar \& Wideman, 2014). Other research found that embracing UDL can eliminate the learning gap between able and disabled learners (Hall et al., 2015). Despite the fact that UDL can be implemented in traditional learning settings (physical classrooms), the use of educational technologies can promote its application (Bühler \& 
Fisseler, 2007; Kumar \& Wideman, 2014). Hence, CAST (2011) concluded that "technology is not synonymous with UDL, but it does play a valuable role in its implementation and conceptualization" ( $p$. 10).

The integration of instructional technologies into higher education has progressed to advanced levels in developed countries, whereas it is relatively underused in developing nations (Ali \& Magalhaes, 2008; Faqih, 2016; Matar, Hunaiti, Halling, \& Matar, 2010; Tarus, Gichoya, \& Muumbo, 2015), particularly in Iraq (Al-Azawei, Parslow, \& Lundqvist, 2016). Matar et al. (2010) explored the status of e-learning application in the Middle-East, indicating that all Arab countries in this region are at varying levels of application and integration with Iraq being one of the least successful. According to Elameer \& Idrus (2011), Iraqi universities suffer from a lack of adequate ICT infrastructure, a limited number of computers and laboratories, and limited internet access inside the campus. Furthermore, Iraq has been classified in a low level of ICT use in different life sectors such as business, health, and education (Alhadithi, Idurs, \& Elameer, 2010). This is unsurprising as of the end 2014 only 9\% of the Iraqi population had internet access (Internet World Stats, 2015). In order to support e-learning application in public Iraqi universities, UNESCO has established and funded a new project which is called Ibn Sina, however, Basha, Mnaathr, Alkhayat, \& Jamaludin (2013) indicated that this project is still in its infancy. Al-Azawei, Parslow, et al. (2016) identified several internal and external obstacles that academic staff and students face to adopting e-learning in public-sector Iraqi universities. These barriers include, but are not limited to, low internet bandwidth, insufficient budget, unclear plan, e-learning illiteracy, lack of user motivation, inadequate technical support, inadequate ICT infrastructure, lack of training programs, and unstable security.

This study investigates learner perceptions with regard to the experience of e-learning at a public university in Iraq since respective empirical research remains scant in the Arab world (Al-Mushasha \& Nassuora, 2012; Faqih, 2016). The research adopts TAM as a framework (Davis, 1986). However, TAM was extended by integrating UDL principles in order to cast some light on the extent to which addressing environmental limitations can enhance the prediction of e-learning acceptance. The philosophy behind this integration underlies educational studies that recommend designing e-courses in accordance with effective pedagogical approaches (Bryans Bongey, Cizadlo, \& Kalnbach, 2010; Derouin, Fritzsche, \& Salas, 2005; Govindasamy, 2002). Based on the best of the authors' knowledge, prior research has not examined the effect of UDL principles on technology adoption. Furthermore, meta-analysis reviews of UDL adoption show that further evidence-based UDL research in higher education is needed, where the model has been mostly implemented in the USA with little to no empirical research being conducted in the Middle-East (Al-Azawei, Serenelli, \& Lundqvist, 2016; Mangiatordi \& Serenelli, 2013; Rao et al., 2014).

\section{Learning Technologies and UDL Application}

The potential of designing accessible curricula by using e-learning has been discussed in literature. Seale and Cooper (2010) concluded that e-learning should be blended with effective pedagogical approaches to deliver accessible learning and meet learner needs. As such, many studies have identified the great effect of using educational technologies on designing and implementing UDL-based inspired courses (He, 2014; Kumar \& Wideman, 2014; Rose \& Strangman, 2007; Smith \& Harvey, 2014).

Bryans Bongey et al. (2010) used course management systems (CMS), WebCT/Blackboard, to design a UDL-based blended e-biology course. A total of 50 students completed the end of course survey. All of 
them confirmed that they use e-learning systems as a part of their course experience. By comparing learner performance and the usage of the course site with the previous semester, it was shown that even though academic achievement was not significantly different, the usage of e-learning was higher than in the previous course. In addition, learners were highly satisfied in the UDL-based blended course. Similarly, the effect of using video integrated closed captions as one aspect of UDL on learner attitudes towards educational technology was investigated by Dallas, Mccarthy, and Long (2016). The results showed that the use of video closed captions had a significant positive influence on student attitudes towards using this educational technology.

Another literature has established a theoretical relationship between UDL-inspired course design and e-learning use. Morra and Reynolds (2010) stated that the use of learning technology alone will not assist to improve learning outcomes. Hence, the authors suggested that integrating UDL principles into instructional technologies and e-course design can lead to such enhancement. Furthermore, BentonBorghi (2013) proposed a theoretical model based on UDL and technological pedagogical content knowledge (TPACK) framework. The simple notion behind TPACK is that teachers need to know how technology should be effectively integrated into teaching. In other words, it provides a coherent conceptual model of how teachers should be prepared to use technology. Benton-Borghi (2013) established that the incorporation of UDL principles and TPACK can promote the use of technology in teaching and learning.

\section{Research Framework}

Since the 1980's, a growing body of research has been theoretically and empirically developed to examine the diffusion and acceptance of Information Systems (IS). The root of such models is grounded in Information Technology (IT), psychology, and sociology (Venkatesh, Morris, Davis, \& Davis, 2003). From the proposed theories, several models have been dominant because of their strong theoretical base, power to identify technology acceptance, and their impacts on other models. According to recent meta-analysis reviews conducted by Hwang, Al-Arabiat, and Shin (2015), Šumak, Heric ``ko, and Pušnik (2011), and Venkatesh et al. (2003), such theories include, but are not limited to, Theory of Reasoned Action (TRA) (Ajzen \& Fishbein, 1980), Theory of Planned Behaviour (TPB) (Ajzen, 1985), Technology Acceptance Model (TAM) (Davis, 1986), Augmented Version of TAM (A-TAM) (Taylor \& Todd, 1995), Technology Acceptance Model 2 (TAM2) (Venkatesh \& Davis, 2000), Unified Theory of Acceptance and Use of Technology (UTAUT) (Venkatesh et al., 2003), and Technology Acceptance Model 3 (TAM3) (Venkatesh \& Bala, 2008). This study takes TAM as its central research focus, the reasons for which is discussed below.

According to Bagozzi (2007), the most acknowledged strength of TAM is its "parsimony." Furthermore, it is easy to be implemented and evaluated due to its simplicity (Hwang et al., 2015). In addition, the soundness of the model has been supported in different settings and technologies (Hwang et al., 2015). Accordingly, it is steadily employed in order to assess the acceptance of a particular technology (Bagozzi, 2007; Hwang et al., 2015). The model is also thought to be one of the most influential theories in IT research (Benbasat \& Barki, 2007; Lee, Kozar, \& Larsen, 2003). TAM, however, fails to illuminate the design process behind the technology adoption behaviour (Venkatesh \& Davis, 2000).

Accordingly, literature that utilised TAM to investigate e-learning acceptance incorporated other factors that relate to e-learning or e-courses design such as online course design and user interface design (Liu, 
Chen, Sun, Wible, \& Kuo, 2010), multimedia instructions (Liaw, 2008), e-course quality and diversity of assessments (Sun, Tsai, Finger, Chen, \& Yeh, 2008), e-content quality (Teng, 2015), as well as eresources quality and participants motivation (Kannan \& Narayanan, 2015). Wixom and Todd (2005) highlighted three approaches of TAM extension: (1) introducing variables from prior research, (2) integrating additional belief variables, and (3) investigating moderators of perceived usefulness and ease of use.

This study focuses on the impacts of addressing curricula limitations on the use of learning technology. According to Seale and Cooper (2010), even though literature has discussed the use of e-learning to design accessible curricula, the pedagogical aspects of this design is neglected. Previous literature has investigated TAM in traditional e-learning settings, whilst the present research purposively embraced UDL principles as a pedagogical framework. Furthermore, perceived satisfaction and e-learning selfefficacy were also merged into the proposed model. Figure 1 demonstrates the main relationships among the original TAM constructs (Davis, Bagozzi, \& Warshaw, 1989).

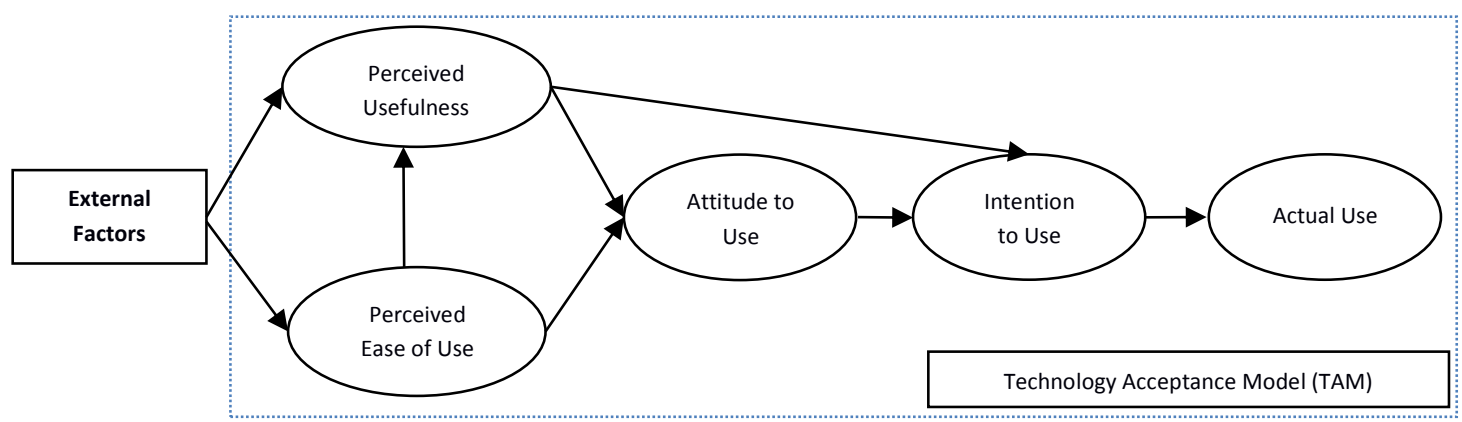

Figure 1. Original TAM constructs (Davis et al., 1989).

\section{TAM}

The theoretical base of the present study was grounded on TAM (Davis et al., 1989). The main factors of the model were inspired by the Theory of Reasoned Action (TRA) (Ajzen \& Fishbein, 1980). TAM suggests that two types of beliefs are a determinant of user attitude and behavioural intention. It establishes a causal link among perceived ease of use (PEOU), perceived usefulness (PU), attitude to use (ATU), and intention to use (ITU). PU pertains to user beliefs that the adoption of a particular technology can improve his/her performance, whereas PEOU refers to the extent of mental effort that is required to use a technology (Davis, 1986). ITU is defined as a user's cognitive representation of his/her willingness to accomplish certain behaviours (Ajzen \& Fishbein, 1980). TAM hypothesises that PEOU has a direct influence on PU and ATU, whilst PU has a direct impact on ATU and ITU. Moreover, ATU has a direct effect on ITU. Recent TAM revision simplified the model by excluding ATU (Venkatesh \& Davis, 2000). In brief, the main hypotheses of TAM are:

H1: PEOU significantly influences PU.

H2: PEOU significantly influences ITU.

H3: PU significantly influences ITU. 


\section{Perceived Satisfaction (PS)}

According to Bolliger and Wasilik (2009), the value that students perceive regarding their learning experience in the educational institution is referred to as perceived satisfaction (PS). Learner dissatisfaction may lead to withdrawing from e-courses or weaker performance. Many studies have integrated a wide range of factors to highlight the predictors of PS (Al-Azawei \& Lundqvist, 2015; Bolliger \& Wasilik, 2009; Sun et al., 2008). In keeping with previous studies, perceived satisfaction (PS) has been significantly affected by PU and PEOU (Barrio-García, Arquero, \& Romero-Frías, 2015; Sun et al., 2008; Weng \& Tsai, 2015). Thus, the implications of these two constructs (PEOU and PU) on PS were investigated as well.

H4: PEOU significantly influences PS.

H5: PU significantly influences PS.

\section{UDL Model}

Rovai (2004) pointed out that learner needs should be considered in the design of e-learning curricula. Similarly, Govindasamy (2002) confirmed that "it has become clear that the impact of not considering the underlying pedagogical principles when implementing e-Learning will undermine the implementation process" (p. 296). Moreover, Rienties and Toetenel (2016) stated that learning design according to an efficient pedagogical theory has a positive direct impact on student behaviour, outcomes, and satisfaction in blended and online learning environments.

UDL is a pedagogical framework that attempts to address the issue of learner differences by designing a flexible and accessible curriculum. Although it can be implemented in traditional learning settings, the use of learning technologies can improve its application (Bryans Bongey et al., 2010; CAST, 2011). Accordingly, this study suggests that integrating learning technology to address curricula limitations may enhance user intentional behaviour to adopt e-learning. Previous studies have quantitatively investigated the influence of e-course design, assessment methods, and multimedia instructions on perceived satisfaction, usefulness, and/or technology adoption (Liaw, 2008; Liu et al., 2010; Sun et al., 2008).

As previously discussed, literature that investigated the UDL implementation on learner perceptions such as engagement, satisfaction, learning flexibility, and social interaction indicated that the three layers of the model significantly affect such perceptions (Davies et al., 2012; Hall et al., 2015; Kumar \& Wideman, 2014). Based on this discussion, the present research hypothesises that designing e-courses in accordance with UDL principles has a direct significant impact on PS and ITU. Moreover, it was expected that the three principles are predictors of PU.

H6a: MMR significantly influences ITU.

H6b: MMAE significantly influences ITU.

H6c: MME significantly affects ITU.

H7a: MMR significantly influences PS.

H7b: MMAE significantly influences PS. 
H7c: MME significantly affects PS.

H8a: MMR significantly influences PU.

H8b: MMAE significantly influences PU.

H8c: MME significantly influences PU.

\section{E-Learning Self-Efficacy (ELSE)}

As a cognitive construct, self-efficacy (SE) was defined as "beliefs about one's own capability to accomplish a certain task by one's own actions and resources even in the face of obstacles or barriers" (Sniehotta, Scholz, \& Schwarzer, 2005, p. 145). According to Bandura (1990), people's beliefs about their capabilities can influence their choices, the effort that they should exert, and the time that they will persevere in order to face difficulties. ELSE was indicated to be a significant predictor of PEOU and/or PU (Al-Azawei \& Lundqvist, 2015; Ong \& Lai, 2006; Venkatesh \& Davis, 2000). Hence, it was expected that learners with high ELSE are more likely to possess higher PEOU and PU than students with low self-efficacy.

H9: ELSE significantly influences PU.

H10: ELSE significantly influences PEOU.

Figure 2 depicts the proposed factors in the research framework.

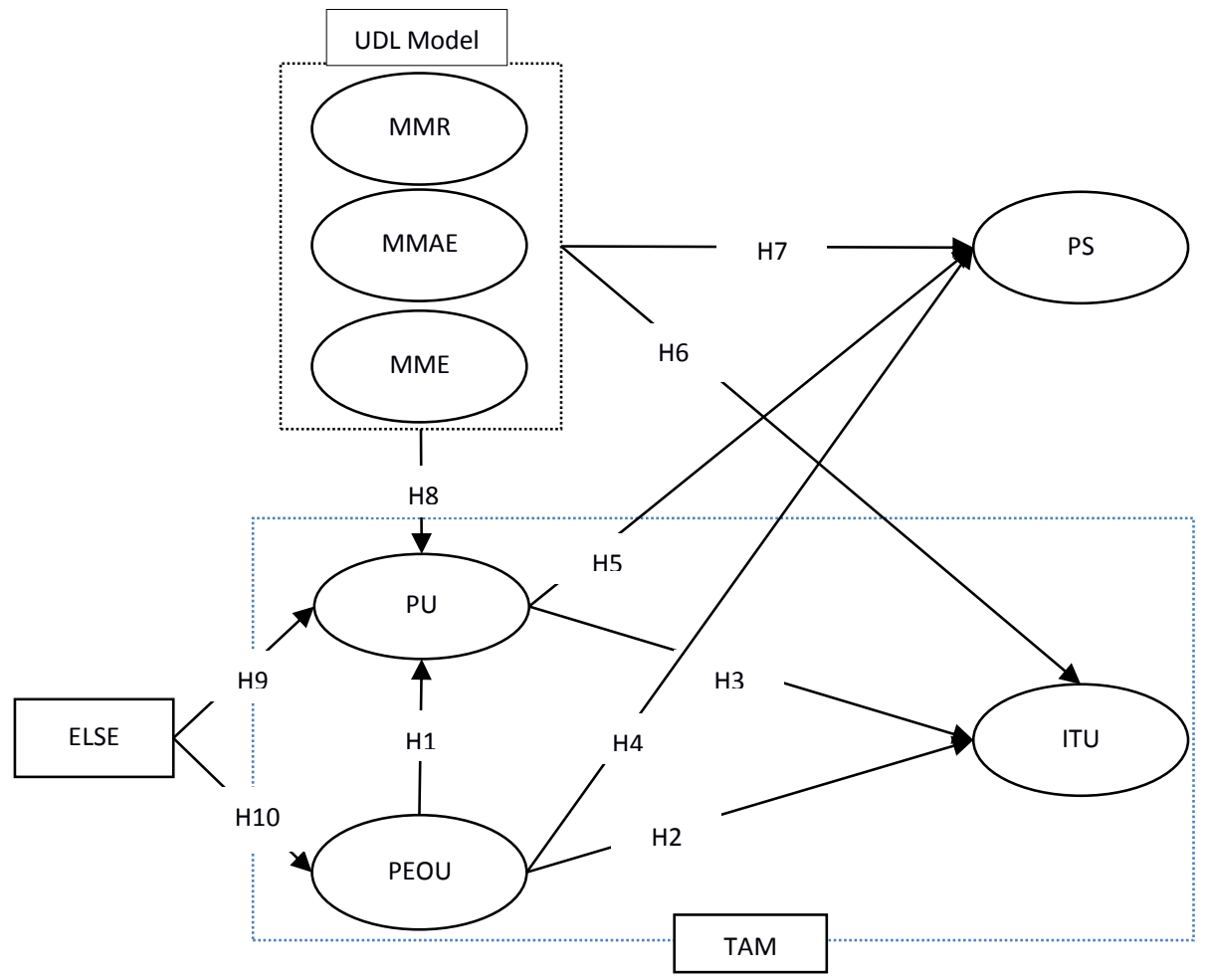

Figure 2. The research framework. 


\section{Research Methodology}

This study sought to identify the effectiveness of UDL implementation on learner satisfaction and intention-behaviour to accept e-learning. It followed a mixed research design, combining action and survey methods. According to Leedy and Ormrod (2005), survey research design is an adequate method for research that aims to identify the causal relationship between dependent and independent variables. Action research, on the other hand, is useful in scrutinizing a particular phenomenon when researchers take a part in the action (Sagor, 2000). According to Sagor (2000), one of the objectives of using action research in education is to meet the individual needs of a wide-mix of learners. However, action research broadly focuses on qualitative data, whereas quantitative analysis is rarely used with this method (Sagor, 2000). Because the present research aims to quantitatively explore the effect of UDL application on technology acceptance, it was designed in accordance with both survey and action research methods.

As aforementioned, effective pedagogical approaches should be taken into consideration in the design of e-learning courses in order to serve learner needs (Bryans Bongey et al., 2010; Govindasamy, 2002; Rovai, 2004). However, there is a noticeable scarcity of such research. The present study was conducted throughout half an academic course in the first semester of the academic year 2015-2016. The first author developed the course design in accordance with UDL principles. The course was delivered using blended learning encompassed in class lectures and the use of Moodle. The design considered the representation of learning content, the methods of knowledge expression and assessment, and the means of student engagement. Moodle was widely used in this course to deliver learning content in multiple means, engage students, notify them about upcoming activities, discuss learning content, upload assignments, and perform online theoretical exams.

\section{Participants}

The research sample was selected based on a non-probabilistic method. This approach enables researchers to choose subjects according to their availability and based on researchers' criteria (Tarhini, Hone, \& Liu, 2015). Out of 115 second-year undergraduate students enrolled in a web design module at a public university in Iraq, 92 (80\%) voluntarily responded to the distributed questionnaire. Most of the respondents ranged in age from 18 to 22 and were $52.2 \%$ male. The ethnicity of all of them was Iraqi Arab and none had any type of hearing or vision impairments. All participants were comfortable with Moodle because they used it during their first year. However, most of them have described their internet and e-learning level as "less experience." The profile information of the subjects is summarised in Figure 3 . This group of participants was used as an experimental group. 


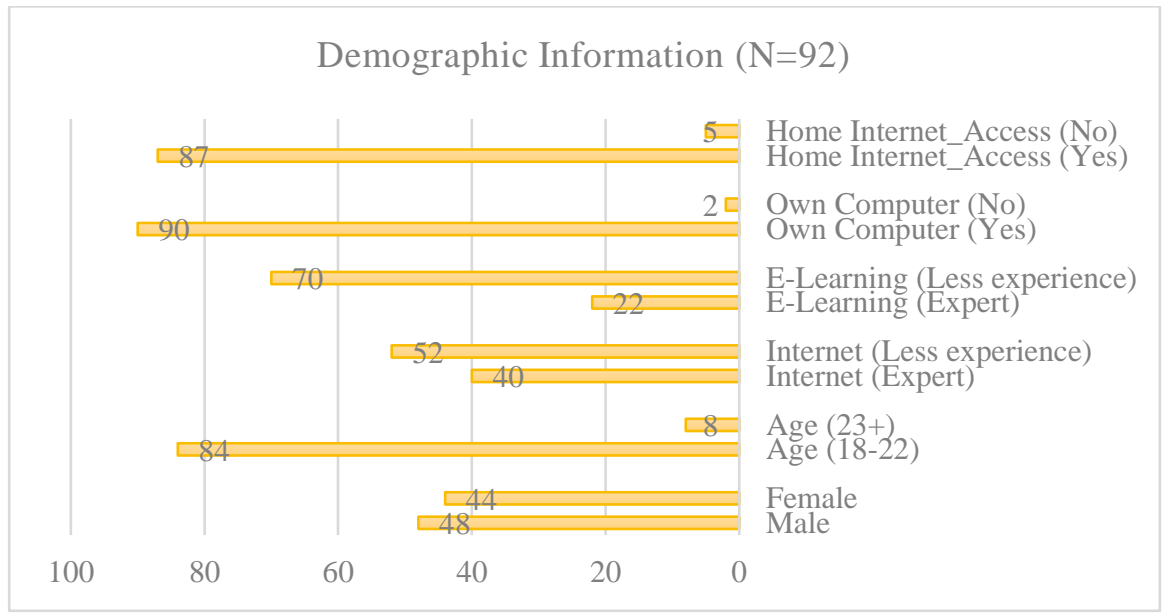

Figure 3. Profile of participants (experimental group).

For further analysis, data of students who experienced e-learning in the traditional setting (without embracing UDL principles) was used as a control group. A total of 77 second year undergraduate students from the previous academic year (2014-2015) completed all items of the research survey (except for UDL variables), they belong to the same college, and experienced Moodle for one academic year as well. The age of the majority of them ranged from 18-23 ( $\mathrm{N}=74,96.1 \%)$. Furthermore, gender split was 39 (50.64\%) male and 38 (49.36\%) female learners. Thus, the overall features of both groups are similar.

\section{Context}

The research subjects were from a computer science college. All laboratories at the college have been connected by a central network and both academic staff and students had Wi-Fi internet access inside the college. At the beginning of the course, students were informed that it will be delivered using a blended learning design. This module was a mandatory course. It covered the main principles of website design by using HTML (HyperText Markup Language), CSS (Cascading Style Sheet), and JavaScript. These three languages (HTML, CSS, and JavaScript) complement each other to design interactive websites. The first five lectures included general concepts of web design and HTML. These lectures were carefully designed to embrace UDL principles as follows:

Multiple means of representation. In order to meet this principle, the learning content was presented in a wide range of formats. All learning materials were designed to explain the same learning content, but by multiple means. The syllabus and grading procedures were presented in the first lecture. Additionally, a course overview that included PDF, Word, PowerPoint files, and video were posted on the course LMS a week before commencement. Then, each lecture was uploaded at least two days before a class session, in order to provide students with a general view about the coming lecture. According to Kumar and Wideman (2014), posting learning materials ahead of time prior to the class sessions can reduce learner anxiety. For each lecture, learning materials were posted in PDF version (including all details about a lecture; the most important concepts were highlighted in different colours and fonts), an equivalent word file (this is to give students more flexibility to maximise or minimise the text font according to their preferences), and a PowerPoint file that included the main outlines of a lecture, its goals, examples, and summary. Furthermore, a detailed explanation for each lecture was also provided using a series of short videos integrating closed notes and illustrations. The length of each video was less than 10 minutes in order to avoid the issue of low internet bandwidth in Iraq. The video 
lectures were designed as follows: an introductory short video that briefly reviewed the concepts discussed in the previous lecture, asking some general questions that students were called to answer in order to continue with the new concepts, and introduced the main goals of the lecture; a series of short videos entailing detailed explanation for core concepts with practical implementation; and finally, a short video that summarised the main discussed points.

In the weekly class sessions, the tutor also used multiple means of representation. This comprised of DataShow and PowerPoint slides, smartboard, a class discussion, a brief Q\&A session, and a small group discussion. During laboratory sessions, the instructor used a short one-to-one lecture format to pinpoint the weaknesses of each student and help him/her to address them. Applying such a mixture of methods in classroom and laboratory sessions was essential in order for the instructor to be able to respond to student individual preferences.

Further, text-based guidelines (PDF and Word files) were also posted on Moodle to explain the main structure and requirements of assignments as well as steps that should be followed to design a good website. Moodle was also used to provide students with additional learning resources either for the development of knowledge or to obtain background information. The purpose of this was to eliminate the background knowledge differential between students. A brief summary of two lectures was also uploaded on the course website as PDF and Word files in order to assist students in remembering the main concepts of the lecture as well as understanding how to summarise a lecture. Thus, the course design covered the first principle of the UDL model by integrating multiple means of representation that offered better access to learning content for more students.

Multiple means of action and expression. A wide range of learning evaluation methods was used to allow learners to demonstrate their knowledge and understanding by multiple means. It is worth mentioning that there were some general assessment rules that should be followed by all instructors as a part of the university assessment procedure. As such, the instructor respected these rules. On the other hand, a multiple means of evaluation was incorporated into the course design based on freedom that the lecturer has. Learners had to complete two theoretical exams, a laboratory test, and a final exam. For the theoretical exam that related to this experiment, different question styles were used such as multiple choices, fill-in-the-blank, brief narrative description, and problem-solving. This gave students more flexibility to respond to each question. Furthermore, students could choose which questions to answer. The dominant method that was used to evaluate students' ability to solve problems was a laboratory test. However, the instructor did not use only one test for such assessment because some students could have underperformed due to miscellaneous external circumstances unrelated to their actual understanding. Hence, a weekly assessment method was chosen instead of relying on one test.

According to Rose et al. (2006), the choice of the most suitable assessment method relies on the core goals of a module. This course aimed to improve the abilities of undergraduate students to design an interactive website using HTML, CSS, and JavaScript. Based on this perspective, students were informed in the first week that they should start planning an individual project from the second week using principles of HTML only and then developing it by applying the concepts of CSS and JavaScript. This approach allowed students to empirically experience their comprehensive understanding and knowledge in the course. Students were given a flexible window of six to eight weeks to submit their work, so they could choose the most suitable time according to their schedule and time commitments 
for other courses. The teacher also identified other activities that students were called to complete whether in the class or on Moodle.

Through the LMS, Moodle, four self-assessments were posted where each one was associated with each lecture. This was important not only in assessment, but for learner engagement as well. In addition, students were asked to choose one of two assignment topics that they were more interested in and upload their work on Moodle. Although a deadline was given for the assignment, the lecturer did not impose it strictly. Therefore, students had a choice to select the most convenient due date that fitted their schedule. This flexibility of submission was adopted because the students have not previously experienced doing assignments. Therefore, a strict due date might lead to a low response. A text-based guideline was provided to help them in preparing their reports and a short video was posted instructing them on how to upload their work. Other daily activities were also integrated as part of student assessment. This wide range of evaluation methods met this UDL principle indicated that the sole use of one assessment method is not adequate to address every student preference.

Multiple means of engagement. According to Conner (2016), engagement represents one of the key concerns of educators in contemporary learning. In this study, different engagement methods were followed in both classroom-based sessions and LMS. After registration, a course overview was posted including a general introduction about its importance, its goals, the main topics that were going to be covered, teaching approaches, and assessment methods. The announcement page of the module website, Moodle, was also used to inform students about all upcoming activities. The purpose was to positively impact on student engagement by keeping them up to date about the course. The prior literature showed that using notification tools in e-learning systems can significantly influence technology adoption (Atchariyachanvanich, Siripujaka, \& Jaiwong, 2014). Furthermore, the instructor posted many questions in the course forum in order to motivate students and enhance their interest in the course. The lecturer had a speedy reply to all students' enquiries as well as answering posted questions. Another engagement approach was the use of online self-assessments that were associated with each lecture. The self-assessment tests were designed with a direct feedback for each question as to whether the answer was correct or not. As discussed by Rose et al. (2006), self-assessments play a vital role in student engagement. Pertaining to video lectures, at the beginning of every lecture, many questions that were associated with the previous topic were triggered and students were asked to pause the video until the questions are answered. This method was used to motivate students in order to evaluate their own knowledge and focus on the course content. Daily activities whether in the classroom or the LMS were also considered a part of student assessment to encourage participation in the course, as well as interaction with other peers. Intensive feedback was provided for all students regarding their online assignments and project.

In classroom sessions, the instructor focused on extending student knowledge about the course, motivating them to express their limitations, and giving them further advice and comments to improve their work. Generally, presenting learning content in multiple means and assessing learner knowledge in different ways were aimed to maintain student motivation during the course. Student interest in the course was also shown via their excellent interaction with the LMS as presented in the log files of Moodle.

\section{The Research Instrument and Procedure}

Prior to intervention, ethics approval was obtained by the relevant Ethics Committee. Subsequently, the first author had many online conversations with the course teacher in order to familiarise him with the 
new course design and main principles of UDL. This was followed by a detailed written guide, which encompassed the course plan.

The research data was collected by the research instrument. It required approximately 10-15 minutes to be completed. The questionnaire consisted of four sections. The first one included general information about the participants (Figure 3). The second section comprised 26 items to identify the eight factors of the model. Most questions were adapted from previously examined instruments (Chiu, Hsu, Sun, Lin, \& Sun, 2005; Liaw, 2008; Said, Kirgis, Verkamp, \& Johnson, 2015; Smith, 2012; Venkatesh \& Davis, 2000; Wu, Tennyson, \& Hsia, 2010). All items used a 7-point Likert scale, ranging from 1 for "strongly disagree" to 7 for "strongly agree." The number of items that were used to infer each construct as follows: PEOU (four items), PU (three items), ELSE (three items), PS (three items), MMR (three items), MMAE (four items), MME (four items), and ITU (two items). The third section was designed to collect information about course features and attributes. It was adapted from Kumar and Wideman (2014). Finally, an open-ended question was used to collect qualitative data that can identify learner perspectives. According to Creswell, Klassen, Clark, and Smith (2011), quantitative and qualitative data have to be integrated instead of separating them. Thus, researchers can either support their quantitative analyses or reject them.

At the end of week six, the research questionnaire was posted on the announcement page of the LMS. All students were requested and encouraged to fill in the instrument in their free time. It was demonstrated that their feedback is important to enhance e-learning implementation in public universities in Iraq as well as developing the course design. The questionnaire contained a cover letter that explained general information about the research, its purposes, and how data will be manipulated. It was clarified that all data will be used for research purposes, their instructor will not access the results, and their individual information or identity will not be displayed. As such, students were asked to identify their actual perceptions as this will not affect marking. Moreover, data was gathered by the first author where he has not had a direct relationship with students. All received responses were valid since all items in the questionnaire were identified as mandatory. However, some cases were duplicated due to either a technical issue or some respondents have filled out the online-based survey more than once where the data was hosted by Google Drive. Therefore, all these observations were excluded prior to data analysis. The process of checking duplicated cases was conducted twice.

\section{Analysis Techniques}

This study used Statistical Package for Social Science (SPSS) version 22 and SmartPLS version 3 for Windows 7 to analyse the collected data. Descriptive and traditional inferential statistic tests were conducted via the former, whereas the survey properties and the path associated among the model constructs were analysed using the SmartPLS. The alpha level at 0.05 was adopted. It is noteworthy that all research analyses were based on data of the experimental group, whilst control group data was used to compare learner perceptions and behavioural intention in traditional-based and UDL-based elearning settings only.

\section{Results}

The gathered data was analysed through six phases. In the former, traditional statistical tests were used to measure the correlation between constructs and the differences between groups. In the second phase, the psychometric properties of the research instrument were analysed. Subsequently, the path 
associated between the original TAM constructs was measured to highlight the improvement in the proposed model power. Moreover, the effect of UDL variables on PU, PS, and ITU was tested in order to show their predictability. Then, the research model and hypotheses were investigated. Finally, learner beliefs were compared with those who attended a traditional-based blended learning in the last phase.

\section{Preliminary Analysis}

Table 1 depicts mean and standard deviation (SD) of the model factors. Generally, all mean scores were greater than the midpoint of 3.5 and SD narrowly spread around the mean. This means that subjects possessed positive responses towards all factors in the research model. For further investigation, Skewness (Std. Error=0.251) and Kurtosis (Std. Error=0.498) were also calculated to measure the normality of the data as well as Tolerance and VIF to examine the multicollinearity assumption. It was found that the majority of data was normally distributed and the multicollinearity assumption was not violated as presented in Table 1. Figure 4 depicts the box plot of the model constructs.

Table 1

Descriptive Statistics

\begin{tabular}{lccccccc}
\hline Factor & Item & Mean & SD & Skewness & Kurtosis & Tolerance & VIF \\
\hline ITU & 2 & 6.0489 & 0.62923 & -0.188 & -0.491 & 0.578 & 1.730 \\
\hline PU & 3 & 5.8333 & 0.88881 & -0.636 & -0.007 & 0.563 & 1.776 \\
\hline PEOU & 4 & 5.6766 & 0.92992 & -1.114 & 2.196 & 0.666 & 1.501 \\
\hline ELSE & 3 & 5.2971 & 1.17821 & -1.358 & 1.841 & 0.819 & 1.222 \\
\hline PS & 3 & 5.9022 & 0.68033 & -0.757 & 1.759 & 0.552 & 1.813 \\
\hline MMR & 3 & 6.3080 & 0.82280 & -2.438 & 10.344 & 0.737 & 1.357 \\
\hline MMAE & 4 & 5.7772 & 0.76447 & -1.107 & 2.806 & 0.581 & 1.722 \\
\hline MME & 4 & 5.8696 & 0.79012 & -1.332 & 3.008 & 0.642 & 1.558 \\
\hline
\end{tabular}

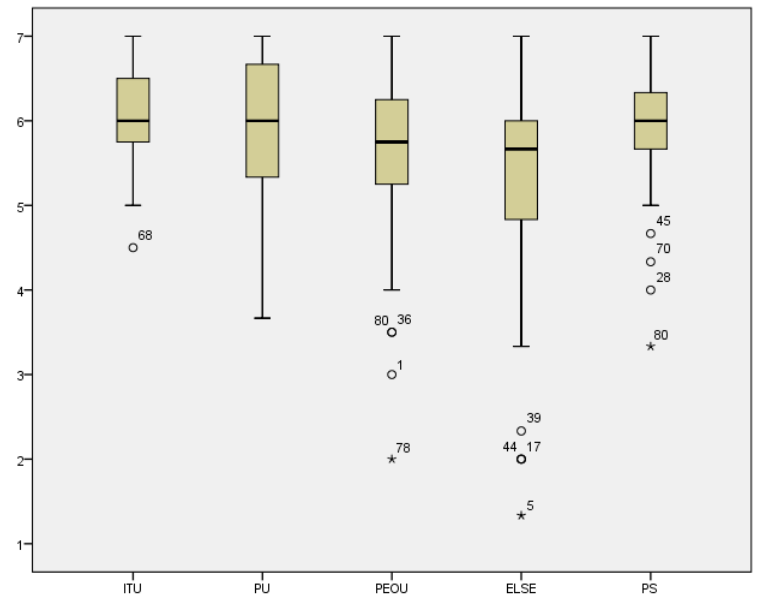

a. TAM variables

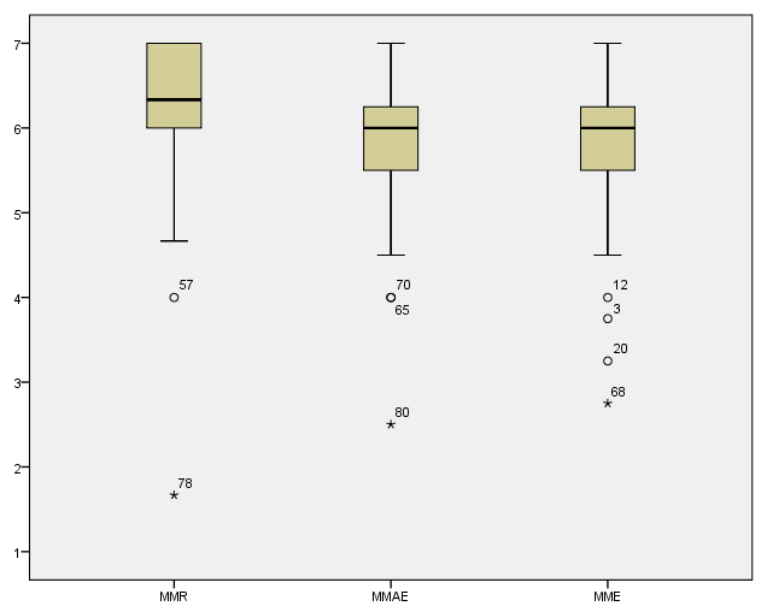

b. UDL variables

Figure 4. Box plot of the model constructs. 
Table 2 shows the findings of independent samples t-test. It was found that there was a statistical significance among internet experience, e-learning experience, and intention to accept e-learning technology. Students with more experience were more likely to adopt e-learning in comparison to less experienced participants. The factors: internet expert, the internet less experience, e-learning expert,

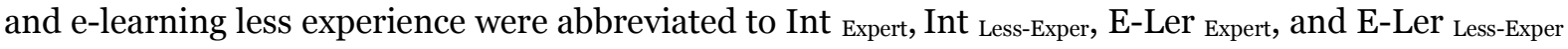
respectively.

Table 3 demonstrates Pearson's coefficient correlation among constructs proposed in this research. There was a significant relationship among most factors and the largest correlation was less than 0.7.

Table 2

Findings of Independent Samples T-Test

\begin{tabular}{|c|c|c|c|c|c|c|c|c|c|}
\hline \multicolumn{5}{|c|}{ Intention to Use (ITU) } & \multicolumn{5}{|c|}{ Perceived Satisfaction (PS) } \\
\hline Factor & $M$ & SD & t-test & $\boldsymbol{P}$ & Factor & $M$ & SD & t-test & $\boldsymbol{P}$ \\
\hline Male & 6.09 & 0.67 & $\mathrm{~T}(90)=0.712$ & 0.47 & Male & 5.93 & 0.70 & $\mathrm{~T}(90)=0.518$ & 0.606 \\
\hline Female & 6.00 & 0.58 & & & Female & 5.86 & 0.66 & & \\
\hline Age $<=22$ & 6.04 & 0.63 & $\mathrm{~T}(90)=0.064$ & 0.94 & Age $<22$ & 5.90 & 0.69 & $\mathrm{~T}(90)=0.118$ & 0.907 \\
\hline Age $>22$ & 6.06 & 0.62 & & & Age $>22$ & 5.87 & 0.50 & & \\
\hline Int Expert & 6.27 & 0.61 & $T(90)=3.169$ & 0.002 & Int Expert & 6.00 & 0.67 & $\mathrm{~T}(90)=1.213$ & 0.228 \\
\hline $\begin{array}{l}\text { Int Less- } \\
\text { Exper }\end{array}$ & 5.87 & 0.58 & & & $\begin{array}{l}\text { Int Less- } \\
\text { Exper }\end{array}$ & 5.82 & 0.68 & & \\
\hline E-Ler Expert & 6.50 & 0.53 & $T(90)=4.191$ & $<0.001$ & $\begin{array}{l}\text { E-Ler } \\
\text { Expert } \\
\end{array}$ & 6.09 & .68 & $\mathrm{~T}(90)=1.502$ & 0.137 \\
\hline $\begin{array}{l}\text { E-Ler Les- } \\
\text { Exper }\end{array}$ & $5 \cdot 90$ & 0.59 & & & $\begin{array}{l}\text { E-Ler Les- } \\
\text { Exper }\end{array}$ & 5.84 & .67 & & \\
\hline
\end{tabular}

Table 3

Pearson Correlation Coefficient Among Variables

\begin{tabular}{|c|c|c|c|c|c|c|c|}
\hline & $\mathbf{P U}$ & PEOU & ELSE & PS & MMR & MMAE & MME \\
\hline ITU & $0.519^{* * *}$ & $0.316^{* * *}$ & 0.010 & $0.371^{* * *}$ & 0.179 & $0.483^{* *}$ & $0.488^{* * *}$ \\
\hline PU & & $0.364^{* * *}$ & 0.033 & $0.480^{* * *}$ & $0.388^{* * *}$ & $0.477^{* * *}$ & $0.485^{* *}$ \\
\hline PEOU & & & $0.330^{* * *}$ & $0.388^{* * *}$ & $0.314^{* * *}$ & $0.311^{* * *}$ & 0.128 \\
\hline ELSE & & & & $0.262^{*}$ & -0.002 & 0.079 & 0.127 \\
\hline PS & & & & & 0.131 & $0.542^{* *}$ & $0.398^{* * *}$ \\
\hline MMR & & & & & & $0.330^{* * *}$ & $0.317^{* * *}$ \\
\hline MMAE & & & & & & & $0.458^{* * *}$ \\
\hline
\end{tabular}

${ }^{*}$ Correlation is significant at the 0.05 level (2-tailed).

${ }^{* *}$ Correlation is significant at the 0.01 level (2-tailed).

\section{Instrument Properties}

To establish the internal consistency reliability of the instrument, Cronbach's alpha ( $\alpha$ ) was measured. Researchers recommend that Cronbach's alpha is acceptable when it exceeds 0.7 (Pallant, 2013). However, Hair, Black, Babin, Anderson, \& Tatham (2006) suggest that Cronbach's alpha is also acceptable if it exceeds 0.6 for exploratory research. Overall, the instrument achieved a good reliability $(\alpha=0.881)$. Furthermore, in order to establish convergent validity, Hair et al. (2006) suggest that both the average variance extracted (AVE) and composite reliability (CR) should be above 0.5 and 0.7 respectively. Another measurement that can be used to validate a questionnaire is called discriminant 
validity. According to Fornell and Larcker (1981), this can be established when the variance that a variable shares with its own constructs is larger than the variance that it shares with other factors. Table 4 clearly depicts that the measurement met all recommendations where Cronbach's alpha ranged from 0.677 to 0.901 , the AVEs were all above 0.5 , and all above 0.8 for CR. A low $\alpha$ for ITU variable could be due to its high mean (6.048) and low SD (0.629).

Table 4

The Measurement Properties

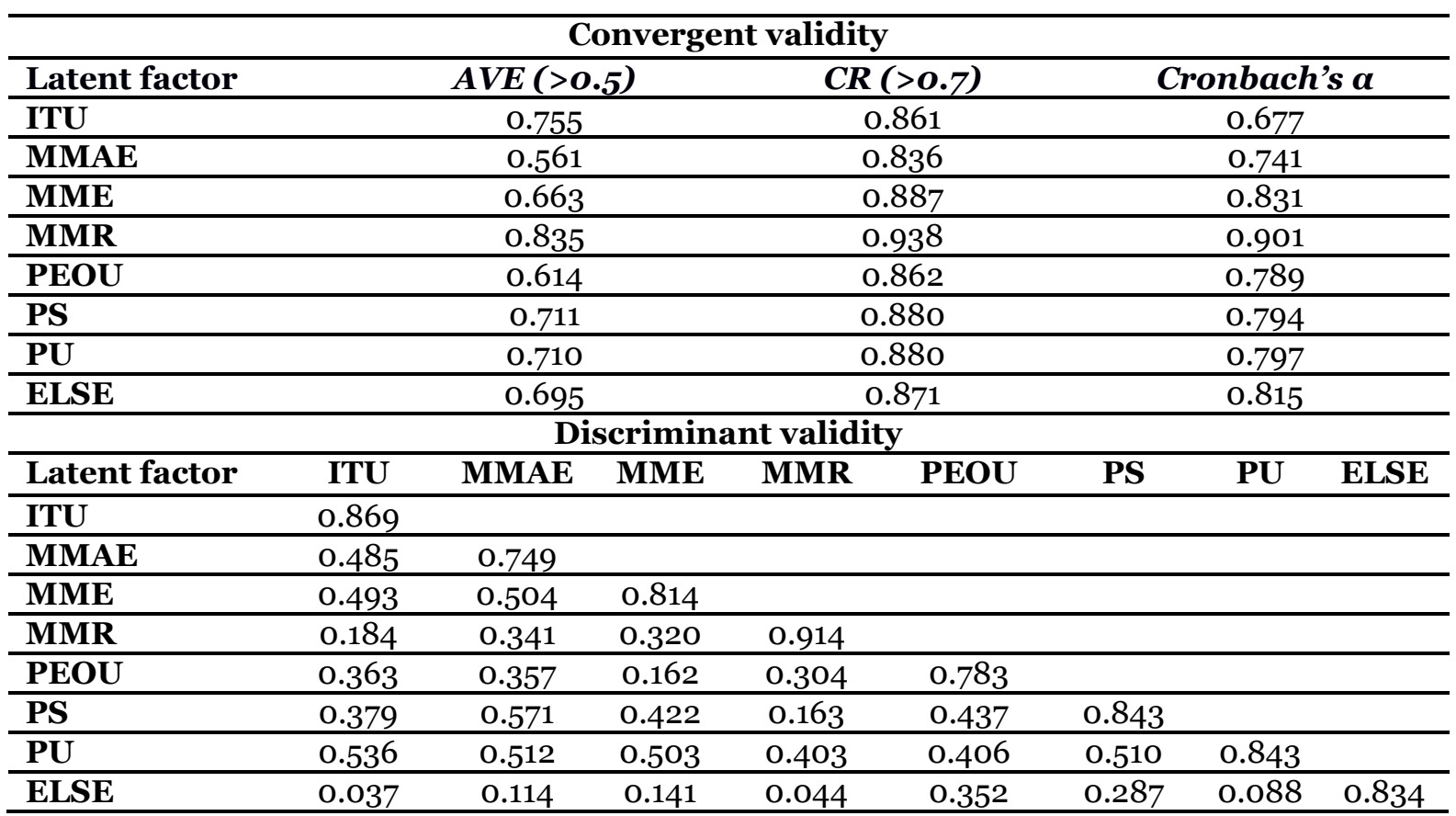

\section{Structural Equation Model (SEM)}

Lowry and Gaskin (2014) recommend two methods of determining the number of observations required for the application of SEM technique. The first suggests that the smallest sample size can be identified by 10 , multiplied by the largest number of variables used to determine a particular construct. The second method recommends a statistical power of regression set at $80 \%$ and an alpha level of 0.05 . Based on both recommendations, the minimum required sample size is either 50 or 91 cases respectively. As such, our sample was adequate to carry out this analysis $(\mathrm{N}=92)$.

PLS-SEM is a popular approach to investigate the association between model factors (Yi \& Hwang, 2003; Zogheib, Rabaa, Zogheib, \& Elsaheli, 2015). This is due to its ability to deal with small sample sizes (Cheng \& Chau, 2014), develop a theory (Hair et al., 2006), and there is no specific assumption about data distribution (Cassel, Hackl, \& Westlund, 1999).

\section{The Investigation of Original TAM Factors}

Before examining the path associated among the proposed model constructs, the association among the original TAM factors (PU and PEOU) was investigated first. The aim of this analysis was to show the improvement in the research model after integrating the UDL variables. Table 5 and Figure 5 illustrate that all factors were predictors of PS, whereas PEOU was not a significant determinant of ITU. The 
factors explained $31.8 \%$ and $31.5 \%$ of the variance of PS and ITU respectively. Such outcomes confirm that TAM should be extended by other factors to improve its power.

Table 5

The Effect of PU and PEOU on PS and ITU

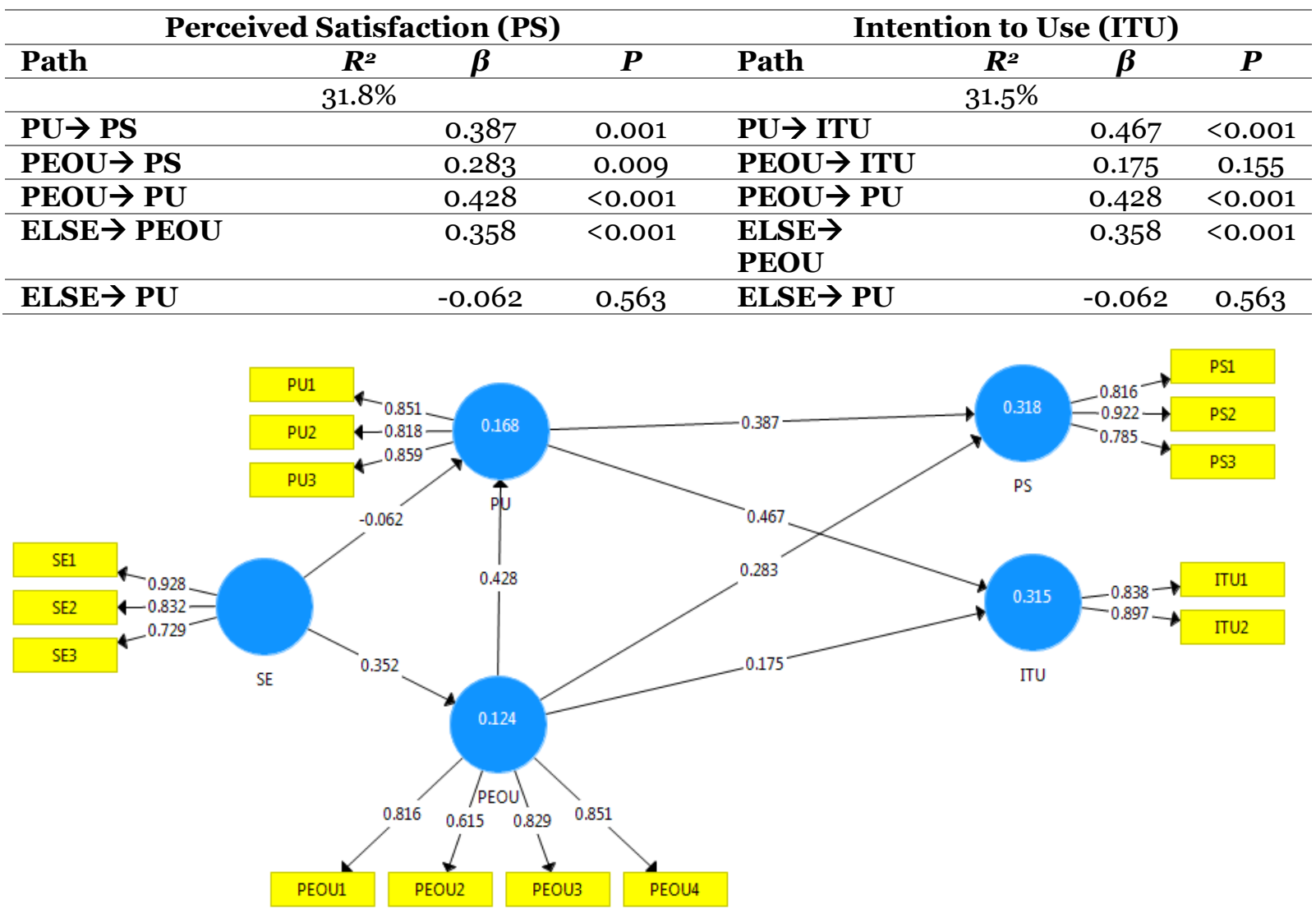

Figure 5. The findings of the original model.

\section{UDL Principles as Predictors of the Model Factors}

For further analysis, the predictability of UDL principles on the dependent variables was examined. This analysis casts more light on the effect of UDL principles on learner perceptions and e-learning adoption. Figure 6 and Table 6 demonstrate that UDL principles have an acceptable fit to explain the dependent constructs. MMAE $\left(\beta_{M M A E} \rightarrow I T U=0.328, P=0.001\right)$ and MME $\left(\beta_{M M E} \rightarrow I T U=0.338, P=0.005\right)$ were determinants of ITU with the prediction ability of $32 \%$. These two constructs MMAE $\left(\beta_{M M A E} \rightarrow P S=\right.$ $0.498, P<0.001)$ and $\operatorname{MME}\left(\beta_{M M E} \rightarrow P S=0.193, P=0.040\right)$ had also significant positive impacts on PS where they explain $35.6 \%$ of this dependent construct. Finally, the three principles had a positive effect on PU with MMAE $\left(\beta_{M M A E} \rightarrow P U=0.297, P=0.008\right)$ and $\mathrm{MME}\left(\beta_{M M E} \rightarrow P U=0.287, P=0.001\right)$ as significant predictors of PU to explain $38.1 \%$ of its variance. 


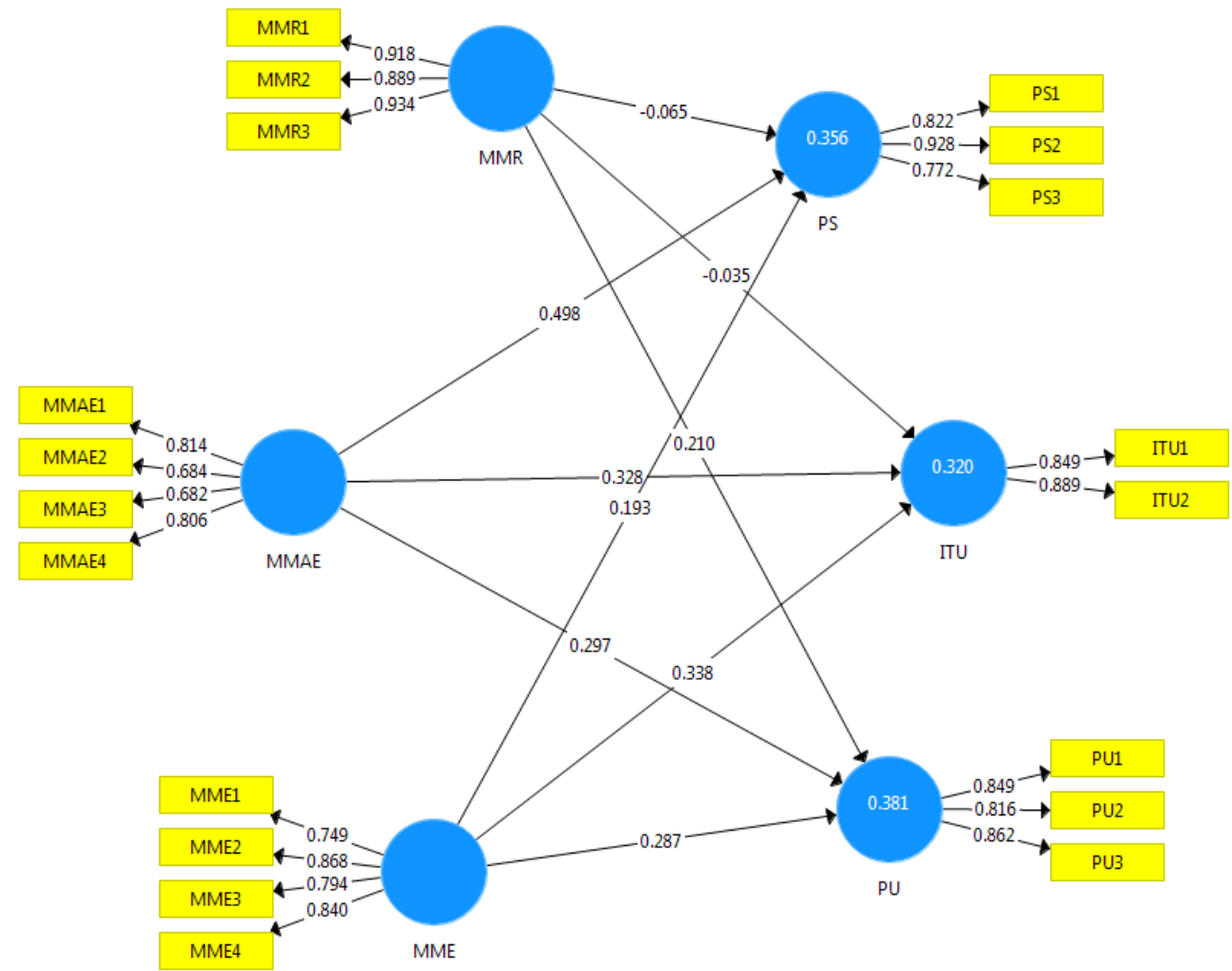

Figure 6. The effect of UDL variables on the model constructs.

Table 6

The Prediction Ability of UDL Principles on ITU, PS, and PU

\begin{tabular}{|c|c|c|c|c|}
\hline \multicolumn{5}{|c|}{ Intention to Use (ITU) } \\
\hline Path & $\boldsymbol{R}^{2}$ & $\boldsymbol{\beta}$ & t-value & $\boldsymbol{P}$ \\
\hline & $32 \%$ & & & \\
\hline MMR $\rightarrow$ ITU & & -0.035 & 0.313 & 0.755 \\
\hline MMAE $\rightarrow$ ITU & & 0.328 & 3.481 & 0.001 \\
\hline MME $\rightarrow$ ITU & & 0.338 & 2.798 & 0.005 \\
\hline & & Satisfac & & \\
\hline Path & $\boldsymbol{R}^{2}$ & $\boldsymbol{\beta}$ & t-value & $\boldsymbol{P}$ \\
\hline & $35.6 \%$ & & & \\
\hline MMR $\rightarrow$ PS & & -0.065 & 0.706 & 0.480 \\
\hline MMAE $\rightarrow$ PS & & 0.498 & 4.355 & $<0.001$ \\
\hline MME $\rightarrow$ PS & & 0.193 & 2.060 & 0.040 \\
\hline & & Usefulr & & \\
\hline Path & $R^{2}$ & $\boldsymbol{\beta}$ & t-value & $\boldsymbol{P}$ \\
\hline & $38.1 \%$ & & & \\
\hline MMR $\rightarrow$ PU & & 0.210 & 1.793 & 0.074 \\
\hline MMAE $\rightarrow$ PU & & 0.297 & 2.684 & 0.008 \\
\hline MME $\rightarrow$ PU & & 0.287 & $3 \cdot 312$ & 0.001 \\
\hline
\end{tabular}

\section{Findings of the Research Framework}

Table 7 and Figure 7 illustrate the standardised path coefficient among the variables in the research framework. Six out of 16 hypothetical associations were confirmed $(P<0.05)$ whereas findings of five hypotheses were on the border of significant. Therefore, it was expected that a larger sample may show 
better results and support more hypothetical associations. $\mathrm{PU}(\beta=0.288, P=0.019)$ and $\mathrm{MME}(\beta=0.270$, $P=0.044$ ) had a positive direct effect on ITU. These outcomes supported H3 and H6c. PEOU and MMAE had a direct positive influence on ITU, but insignificant where $P$ values are 0.098 and 0.073 for both variables respectively. The factors accounted for $41.6 \%$ of the variance of ITU where PU had the largest impact. Additionally, the findings indicated that PEOU $(\beta=0.252, P=0.005)$ and $\mathrm{MMAE}(\beta=0.356$, $P<0.001$ ) had a direct influence on PS. Thus, hypotheses $\mathrm{H}_{4}$ and $\mathrm{H} 7 \mathrm{~b}$ were confirmed. PU and MME had also a direct positive effect on PS, however, it was not significant where $P$ values are 0.094 and 0.124 for both factors. Overall, these constructs accounted for $45.4 \%$ of the variance of PS. To predict PU, MME ( $\beta=0.313, P=0.001)$ was found to have a significant effect on this variable as hypothesised in H8c, whereas PEOU had a direct positive insignificant impact $(P=0.066)$. Finally, it was indicated that ELSE $(\beta=0.352, P<0.001)$ had a positive influence on PEOU. Accordingly, H10 was retained.

Table 7

Findings of the Research Hypotheses

\begin{tabular}{lccccccc}
\hline \multirow{2}{*}{ Hypothesis } & \multicolumn{7}{c}{ Standardised estimate } \\
\cline { 2 - 8 } & $\begin{array}{c}\text { Direct } \\
\text { effect }\end{array}$ & $\boldsymbol{t}$ & $\boldsymbol{P}$ & $\begin{array}{c}\text { Indirect } \\
\text { effect }\end{array}$ & $\boldsymbol{t}$ & $\begin{array}{c}\text { Total } \\
\text { effect }\end{array}$ & Finding \\
\hline H1: PEOU $\rightarrow$ PU & 0.258 & 1.838 & 0.066 & & & 0.258 & Rejected \\
H2: PEOU $\rightarrow$ ITU & 0.177 & 1.655 & 0.098 & 0.074 & 1.205 & 0.252 & Rejected \\
H3: PU $\rightarrow$ ITU & 0.288 & 2.350 & 0.019 & & & 0.288 & Supported \\
H4: PEOU $\rightarrow$ PS & 0.252 & 2.838 & 0.005 & 0.054 & 1.259 & 0.306 & Supported \\
H5: PU $\rightarrow$ PS & 0.209 & 1.674 & 0.094 & & & 0.209 & Rejected \\
H6a: MMR $\rightarrow$ ITU & -0.135 & 0.905 & 0.365 & 0.044 & 1.365 & -0.091 & Rejected \\
H6b: MMAE $\rightarrow$ ITU & 0.184 & 1.792 & 0.073 & 0.063 & 1.389 & 0.247 & Rejected \\
H6c: MME $\rightarrow$ ITU & 0.270 & 2.017 & 0.044 & 0.090 & 1.739 & 0.360 & Supported \\
H7a: MMR $\rightarrow$ PS & -0.167 & 1.304 & 0.192 & 0.032 & 0.949 & -0.134 & Rejected \\
H7b: MMAE $\rightarrow$ PS & 0.356 & 3.639 & $<0.001$ & 0.036 & 1.095 & 0.402 & Supported \\
H7c: MME $\rightarrow$ PS & 0.150 & 1.540 & 0.124 & 0.065 & 1.518 & 0.215 & Rejected \\
H8a: MMR $\rightarrow$ PU & 0.154 & 1.531 & 0.126 & & & 0.154 & Rejected \\
H8b: MMAE $\rightarrow$ PU & 0.219 & 1.806 & 0.071 & & & 0.219 & Rejected \\
H8c: MME $\rightarrow$ PU & 0.313 & 3.309 & 0.001 & & & 0.313 & Supported \\
H9: ELSE $\rightarrow$ PU & -0.078 & 0.839 & 0.402 & 0.091 & 1.546 & 0.066 & Rejected \\
H10: ELSE $\rightarrow$ PEOU & 0.352 & 4.139 & $<0.001$ & & & 0.352 & Supported \\
\hline
\end{tabular}




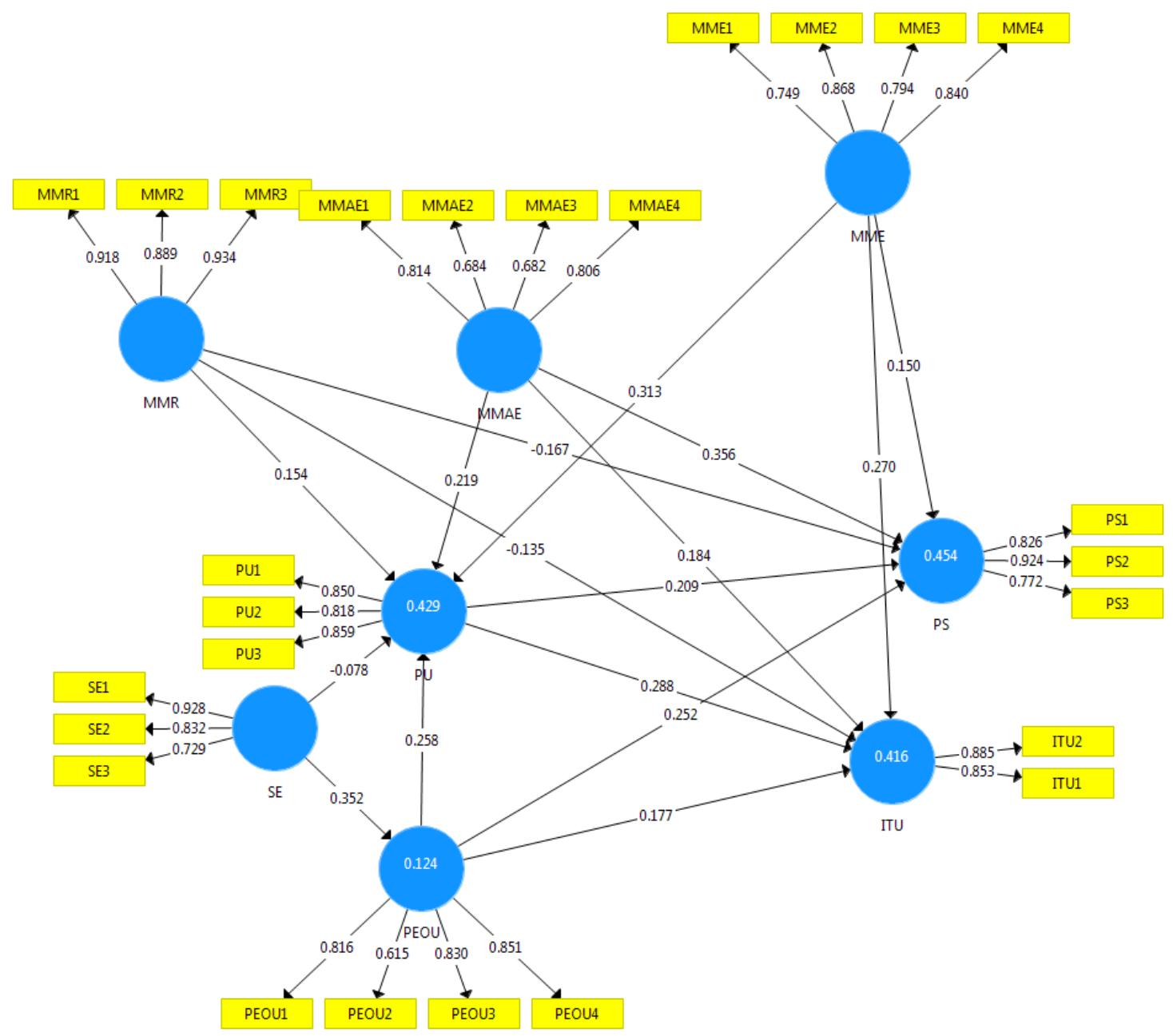

Figure 7. Findings of the research framework.

\section{Comparing ITU, PS, PU of the Experimental and Control Groups}

In order to demonstrate the effect of the UDL-based blended learning design on learner satisfaction, elearning usefulness, and intention to use the system, the findings of this experiment are compared with a group of learners who have completed the same instrument in the previous academic year (2014-2015) where their PU, PS, and ITU were measured in a traditional blended e-learning platform. Table 8 depicts that there is a significant difference among all factors where the mean scores of the second experiment (UDL-based blended learning) are significantly higher than that in the previous year (traditional-based blended learning). Based on this outcome, it can be stated that the design of e-courses in accordance with the UDL framework has a direct significant impact on student perceptions and behavioural intention to accept e-learning.

Table 8

A Comparison Between PU, PS, and ITU of the Experimental and Control Groups (one-way ANOVA)

\begin{tabular}{lcccccc}
\hline Course & $\boldsymbol{N}$ & $\boldsymbol{M}$ & $\boldsymbol{S D}$ & $\boldsymbol{d} \boldsymbol{f}$ & $\boldsymbol{F}$ & $\boldsymbol{P}$ \\
\hline Traditional-Based Blended E-learning & 77 & 5.1688 & $\mathbf{1 . 1 6 1}$ & 1,167 & 17.716 & $<0.001$ \\
\hline UDL-Based Blended E-learning & 92 & 5.8333 & 0.888 & & \\
\hline & \multicolumn{6}{c}{ Perceived Satisfaction (PS) } \\
\hline
\end{tabular}




\begin{tabular}{lcccccc}
\hline Traditional-Based Blended E-learning & 77 & 5.1688 & 1.351 & 1,167 & 20.808 & $<0.001$ \\
\hline UDL-Based Blended E-learning & 92 & 5.9022 & 0.680 \\
& \multicolumn{7}{c}{ Intention to Use (ITU) } \\
\hline Traditional-Based Blended E-learning & 77 & 5.3831 & 1.240 & 1,167 & 20.248 & $<0.001$ \\
\hline UDL-Based Blended E-learning & 92 & 6.0489 & 0.629 & & & \\
\hline
\end{tabular}

\section{Course Attributes, Features, and Content Analysis}

To gain further information about learner preferences in this blended course, students were requested to highlight the most useful materials and helpful attributes. All students responded to the questions about the course features and attributes, whereas some of them provided further qualitative data, identifying reasons for their choice. Students were called to choose the most helpful course attributes and identify why these attributes were helpful. Figure 8 demonstrates the most preferred course attributes and their effects on student learning. Nine attributes were identified for this course. This was followed by an open-ended question to highlight reasons for the helpfulness of a certain attribute. Additionally, from the 15 course materials, students were asked to identify if they accessed them, found them useful, or did not visit the materials. This was also followed by an open-ended question asking for the subjective reasons behind their choices. Figure 9 exhibits student opinions regarding the usefulness of the used materials in the course design.

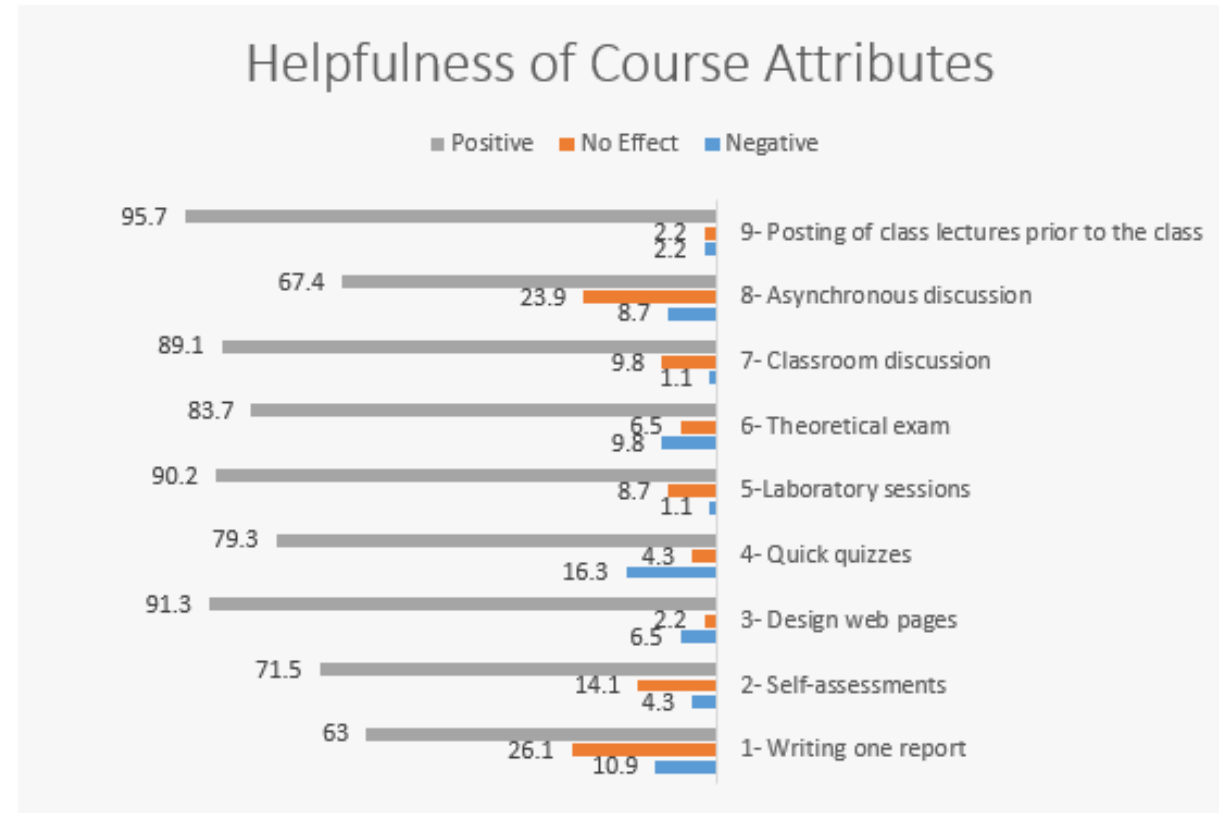

Figure 8. The helpfulness of the course attributes (\%). 


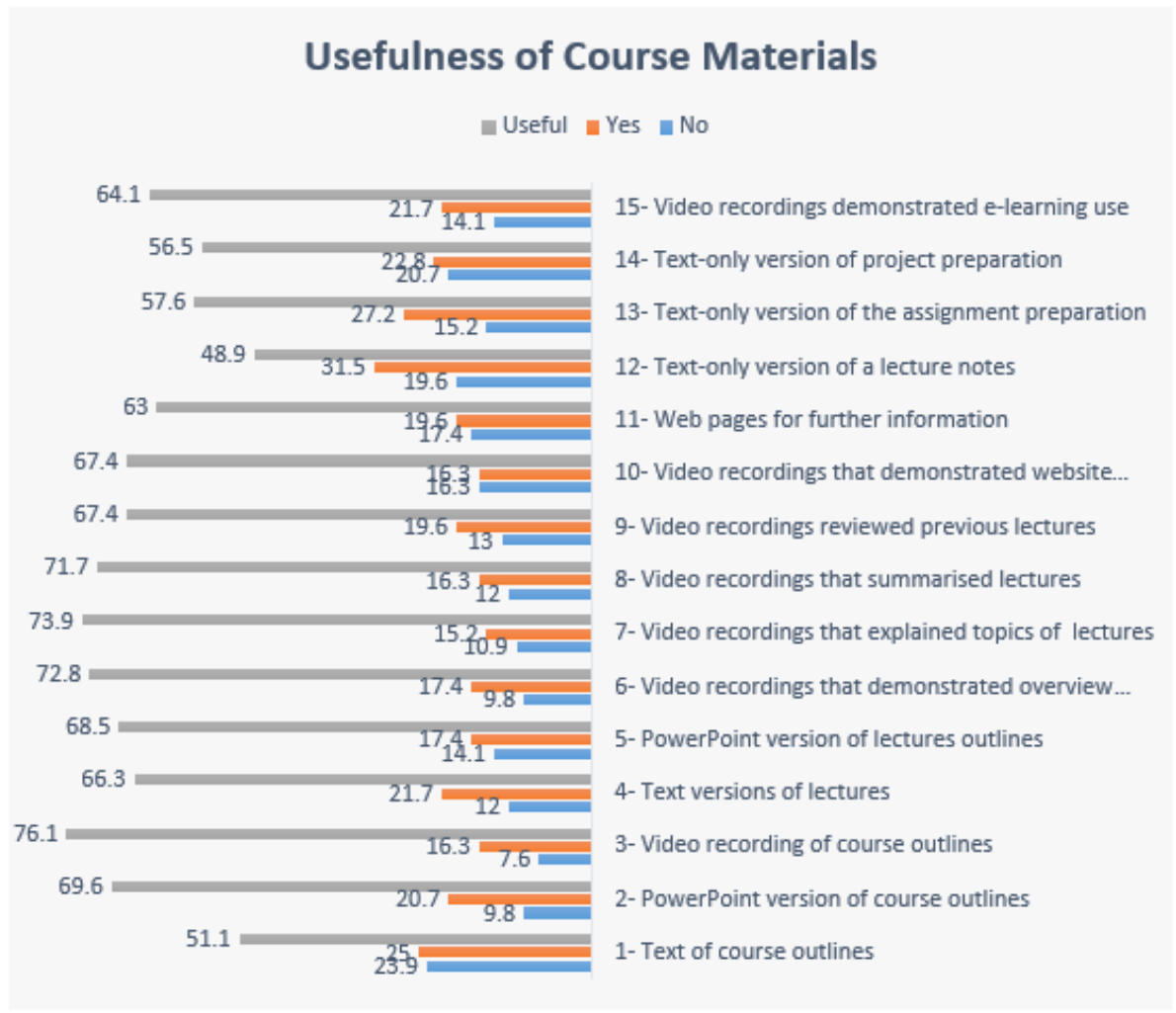

No: did not access, Yes: Access, but not useful, Useful: Access and useful

Figure 9. The usefulness of the course materials (\%).

Participants were also asked to add any comments about the design of the course, the use of e-learning, and its advantages and disadvantages. A total of 23 students responded to this optional open-ended question. A thematic method was used to identify the main themes of students' comments. In general, the participants highlighted four advantages and one obstacle. Table 9 shows the main identified themes as well as the number and percentage of respondents who highlighted similar themes. It is worth mentioning that a few students mentioned more than one advantage.

Table 9

The Generated Themes from the Qualitative Analysis $(N=23)$

\begin{tabular}{lcc}
\hline \multicolumn{4}{c}{ Blended E-Learning Advantages and the Course Design } & \\
\hline Theme & Number & $\mathbf{\%}$ \\
\hline A useful tool in teaching and learning & 10 & 43.47 \\
Improving learning engagement & 3 & 13.04 \\
Reducing learning stress & 3 & 13.04 \\
Enhancing performance, understanding, and interaction & 8 & 34.78 \\
\hline \multicolumn{4}{c}{ The Issue Associated with Blended E-Learning Application } \\
\hline Theme & Number & $\mathbf{\%}$ \\
\hline Unavailability of the internet access & $\mathbf{2}$ & 8.69 \\
\hline
\end{tabular}




\section{Discussion and Implications}

This study extended TAM by considering the UDL principles, namely MMR, MMAE, and MME to analyse the extent to which such factors influence learner satisfaction, e-learning usefulness, and elearning acceptance. The analysis suggests that eliminating learning barriers and responding to user preferences is a key factor to improving learner perceptions and beliefs in a blended learning mode.

Looking to the original model as presented in Table 5 and comparing its prediction power with the extended model can clearly indicate the enhancement in the latter. Whilst the original model accounted for $31.8 \%$ and $31.5 \%$ of the variance of PS and ITU respectively, the proposed framework accounted for $45.4 \%$ and $41.6 \%$ of the variance of both constructs as depicted in Figure 7. Looking to the prediction power of the UDL principles as presented in Table 6 and Figure 6 also reveal that these variables can explain an acceptable fit of variance for PU (38.1\%), PS (35.6\%), and ITU (32\%). Thus, their prediction ability is even better than the original TAM factors as depicted in Figure 5. Moreover, the comparison of learner perceptions and behavioural intention (PU, PS, and ITU) of those who used traditional-based and UDL-based blended e-learning systems shows that the second group had significantly higher perceptions and intention to use e-learning (Table 8). This outcome is in agreement with the study conducted by Bryans Bongey et al. (2010) where they also compared learner satisfaction and e-learning usage of students from two different semesters. The former followed a traditional-based blended learning, whereas the latter adopted a UDL-based blended learning. The findings revealed that elearning use and perceived satisfaction were improved in the second semester. Thus, the present study quantitatively verifies the theoretical suggestion of Morra and Reynolds (2010) and Rose and Strangman (2007) that the integration of UDL into instructional technologies can improve learner experience. Based on these findings, it can be concluded that the integration of UDL principles into e-learning courses design may lead to reducing the e-learning failure in developing countries since learners can realise its advantages rather than using e-learning as a medium of posting written learning materials only.

From the learner profile analysis, the t-test suggests that the internet and e-learning experience have significant impacts on technology acceptance where $P<0.01$ for both variables. Students with greater experience were more willing to use e-learning than those with less. Liu et al. (2010) also exhibited that previous online experience had a significant impact on ITU online learning. Based on these findings, educational institutions, especially in developing countries, should consider the importance of conducting intensive training courses for students in the internet and e-learning technologies to promote their confidence in using them. Other background information such as gender differences and age seem to neither affect PS nor ITU as depicted in Table 2.

Results show that two (PU and MME) out of five suggested constructs were significant determinants of ITU e-learning where PU was the best predictor. Even though Davis et al. (1989) found that PU was more significant in Western cultures, our finding is compatible with studies from other backgrounds and cultures to indicate that PU is the most influential factor on ITU (Barrio-García et al., 2015; Moon \& Kim, 2001; Venkatesh \& Davis, 2000; Yi \& Hwang, 2003). Furthermore, Faqih (2016) compared the effect of perceived usefulness and perceived value on ITU, concluding that PU had the strongest prediction ability as in the present research. Hence, it can be concluded that even though the Arab countries have a different culture than the West nations, users in both cultures believe that the technology usefulness is more important than other factors in the technology adoption. This means that educational institutions need to understand factors that can lead to the enhancement of PU. MME as a core principle in the UDL framework had a significant influence on ITU even better than the original 
factor of TAM (PEOU). This means that different engagement approaches have to be integrated into the design of blended e-courses to promote usage intention. In this research, students were highly engaged in class sessions and via Moodle by exploiting its flexibility and interactive features. Consequently, such engagement methods positively influenced learner intention-behaviour to adopt e-learning. Our findings are compatible with the study performed by Moon and Kim (2001) where they extended TAM by incorporating perceived playfulness as an indicator of intrinsic motivation in order to predict user intention to adopt World Wide Web (WWW). The study concluded that perceived playfulness was a determinant of intentional behaviour. However, PU was the best predictor.

PEOU had a direct impact on ITU, but it did not significantly determine it $(P=0.098)$. This analysis is in agreement with some literature (Balakrishnan \& Gan, 2016; Cigdem \& Ozturk, 2016; Park, 2009; Shin \& Kang, 2015), whereas it contrasts other TAM studies (Weng \& Tsai, 2015). Generally, prior research found that the influence of PU is larger than PEOU even if both have a significant effect on ITU (Venkatesh \& Davis, 2000; Weng \& Tsai, 2015). In the review study conducted by Šumak et al. (2011), it has been found that PEOU was the weakest determinant of ITU. Moreover, Hwang et al. (2015) concluded that the association between PEOU and ITU was contradictory. According to Venkatesh et al. (2003), the influence of PEOU is on the early stage of adoption. In addition, Venkatesh \& Bala (2008) found that PEOU affects ITU in some time periods, but it does not in others. They accounted for these inconsistent results due to the experience level of participants. Hence, our findings may be attributed to: individual e-learning skills of participants since all of them from a computer science field, they have experienced Moodle in their last academic year, and a video with illustration was posted on the course website that illustrated how to use the system. Furthermore, this outcome suggests that student beliefs about learning technology usefulness are more important than beliefs on usage ease. In other words, this may indicate that when students believe a particular technology is useful, they will be willing to continuously adopt it regardless of the required mental effort to use it.

In terms of PU predictors, the strongest one was MME, even more than PEOU. A possible explanation is that engaging learners in different ways assists them to realise the usefulness of e-learning as an optimal solution in serving their needs. ELSE, on the other hand, did not seem to have a direct effect on PU, supporting the findings of Shin and Kang (2015). Even though it was stated in another quantitative analyses that ELSE is a predictor of PU ( Al-Azawei \& Lundqvist, 2015; Park, 2009), the present study confirms the conclusion of Ong and Lai (2006) that the effect of ELSE on PEOU is larger than its influence on PU. Moreover, this outcome may suggest that learners realised the usefulness of this blended learning system regardless of their individual skills to use it. On the other hand, students with less confidence in their individual abilities need further mental effort to perform their tasks appropriately. Such findings emphasise the t-test results (Table 2) that the individual experience in a particular technology can motivate students to use it continuously. As such, the need for carrying out training programs is an essential step in promoting e-learning acceptance.

Following PS determinants, MMAE and PEOU were predictive factors of PS with MMAE as the highest determinant. The significance of MMAE is compatible with the study performed by Sun et al. (2008) where results revealed that a variety of assessment methods was a predictive construct of PS. Moreover, this finding advocates the recommendation of Govindasamy (2002) that the use of different evaluation and assessment methods is a cornerstone of e-learning success. As in other investigations, PEOU was also displayed to be a direct significant antecedent to PS (Weng \& Tsai, 2015). An unexpected result of this analysis is that PU contribution to the prediction of PS had been insignificant. In support of our findings, Sun et al. (2008) found that PEOU impacted on PS more than PU. Our conclusion does not 
necessarily imply that PU is not overall a significant determinant of PS, but it may have been in this instance due to the small sample size. Consequently, the alpha value was $(P=0.094)$ which is on the border of the significant level $(P<0.05)$. The integration of a larger sample size can potentially highlight the importance of PU. Since MMAE is the most significant determinant, instructors can enhance learner satisfaction by exploiting the characteristics of blended learning systems to serve student preferences in the mean of knowledge expression rather than solely relying on one approach. This provides further support to the importance of UDL implementation in blended e-courses.

In order to provide further understanding, the questionnaire included a section regarding the helpfulness and usefulness of the course attributes and materials respectively. Additionally, three openended questions were used to collect qualitative data. A thematic method was adopted to classify such data. The findings of this analysis are demonstrated in Table 9.

Pertaining to the course attributes, Figure 8 demonstrates that posting lectures prior to the class (95.7\%), videos of a website design (91.3\%), laboratory sessions (90.2\%), and classroom discussion (89.1\%) were the most helpful course attributes. This means that several attributes should be integrated into the design of blended e-courses to promote learner motivation and ensure that their individual preferences are met. Here, some of the students' comments are shown:

[I preferred] posting and explaining lectures in the system [Moodle] before the class lecture because I read it before going to the class and when the lecturer explains it, it appears very easy to me.

[I preferred] posting and explaining lectures in the system [Moodle] before the class lecture because I [can] obtain an overview about the topic and translate any unclear terms. . . before explaining them in the class, this helped me a lot.

Designing a website. . . had a great benefit because it assisted us to recall the subject content....and used them to produce an interactive project that exhibits our individual ideas and abilities.

As exhibited in Figure 9, the first principle of UDL is confirmed further. The followed design indicates that the use of multiple means of representations has a potential of integrating the blended e-courses. As shown in Figure 9, students selected several attributes such as video lectures, outlines, text lectures, and animated lectures as useful learning materials. Hence, the learning content should be presented in different ways and this, in turn, can provide better opportunities for absorbing it. However, it is clear from Figure 9 that the most useful materials according to participants were video lectures that explained: the course outlines (76.1\%), details of the lectures content (73.9\%), overview and goals of lectures (72.8\%), and summary of lectures (71.7\%). Accordingly, instructors should integrate multimedia instructions into the design of e-courses rather than using e-learning as a medium of uploading textual materials only. This result is in agreement with the quantitative findings that demonstrated the usefulness of multiple means of representations and multimedia instructions $(\mathrm{M}=6.30, \mathrm{SD}=0.80)$. Moreover, this further supports the high improvement in the prediction of PU where it has been enhanced from $16.8 \%$ before integrating UDL principles to $42.9 \%$ in the proposed framework. Such outcomes are also compatible with the theory of multimedia instructions of Mayer (2009). Even though MMR did not indicate a significant effect on ITU and PS, it shows a positive influence on PU where this analysis supports the usefulness of multimedia instructions. These benefits were also reflected by some of the participants' responses to the open-ended question: 
Video lectures were more beneficial because they contain practical explanations and I can watch the video whenever I want

[I]f I did not understand a topic from the lecturer, I can watch the video lecture to understand the unclear content and attempt to repeat it more than once, [this] helps to understand the topic easily. .. as well as I can keep the video, it explains the subject step by step

The most beneficial material for me was the PowerPoint lectures because the topic is ordered, summarized, and they summarise the important things of the topic

PowerPoint is the most important because it is very neat, easy, and includes the important things

Review of lectures after studying them in details because this recalls [information] for students in a brief and quick form and this, in turn, benefits the student by saving the time [required] to understand the subject.

Table 9 illustrates that five themes have been indicated by students who responded to this optional open-ended question $(\mathrm{N}=23)$. Overall, $(43.47 \%)$ found e-learning is a useful tool that can improve learning and teaching. This is compatible with the results of perceived usefulness $(M=5.83, S D=0.88)$. Furthermore, the subjective data also showed that (13.04\%) of participants believed that this course has engaged them and reduced learning stress. This qualitative finding is compatible with the third principle of UDL framework that suggests using multiple means of engagement to maintain learner attention. Students (34.78\%) also found that this course assisted them to enhance: academic achievement, the interaction with the learning content, and subject comprehension. Thus, this analysis further confirms the conclusion of prior literature that the implementation of UDL can improve the learning process in general (Hall et al. 2015; Kumar \& Wideman 2014). On the other side, a few students highlighted that the unavailability of internet access represented the main barrier to benefitting from the blended ecourse. Although only two students mentioned this obstacle, this can be an indication of the difficulty that some students faced. Below some of the students' comments are reported:

Advantages: it is a gorgeous and very useful design from all sides, video lectures and the used way to display them, notices, preparation of reports, and tests. All of these encourage student[s] to visit the website continuously and rely on themselves to follow, study, and take information... There are no disadvantages to be discussed

I see that it is a useful system that improves a student performance, especially, video lectures and quizzes in the system, they are useful to test ourselves. . . As well as the ease of obtaining lectures from the system which saves time and effort of the student. As well as it provides us the ability to get overview about the lectures before explaining them in the classroom

[S]o learning in this system is enjoyable, I would also like to thank the instructor because he makes the subject easy and enjoyable

E-learning is good, but there are some obstacles such as the difficulty of getting the internet access sometimes inside the university and for all students. There are many advantages of the system [such as] the ease of understanding and the good interaction with the subject

Several theoretical and practical implications follow from the findings of this research. It shows that there is potential for practical application of the present study in the design of online and blended 
learning. Behavioural intention to accept blended learning and learner satisfaction can be significantly improved by considering curricula design. The outcomes suggest that students possessed positive perceptions towards a well-designed blended e-course.

The present experiment represents a significant contribution to the theory of technology adoption by integrating the principles of a pedagogical framework to extend TAM. It reflects the IS model and pedagogical framework, which empirically indicates that addressing environmental limitations can contribute to the enhancement of learner beliefs and perceptions. This means that instructors and researchers should carefully design e-courses, engage students, and apply different approaches to giving students alternative opportunities to absorb a subject, express their understanding, and retain their engagement. Following this design method, the individual needs and preferences of all students can be met. Moreover, it shows that addressing curricula limitations is a cornerstone in educational systems. Consequently, integrating modern learning technologies alone cannot be an optimal solution to improve learning quality. This should be supported by adopting innovative teaching approaches and responding to learner variety in today's education. Embracing UDL principles in e-course delivery reveals a positive impact on learners in accepting learning technology and this, in turn, may lead to better learning outcomes. The study also provides an empirical solution to address e-learning failure since it shows that the incorporation of pedagogical methods into e-learning design can significantly affect user acceptance of a particular learning technology. Finally, the present research advocates the positive role of e-learning in the developing nations, if it is effectively implemented.

\section{Recommendations and Limitations}

Based on the research findings, many recommendations are drawn. First, flexible and blended approaches to learning should be integrated into e-learning in order to enhance its adoption. Therefore, educational institutions need to blending effective learning theories, more especially, UDL principles with e-learning design in order to respond to learner needs and preferences. Furthermore, extensive training programs should be provided for instructors in higher education in order to spread the philosophy of accessible learning theory and familiarise them with the effective approaches to design accessible and flexible learning contents. Additionally, leaderships and those in the position of decisionmaking in the educational institutions need to pay further consideration to the implementation of elearning, and in the developing countries in particular. This is because successful e-learning application has positive impacts on learner engagement, perceptions, and attitudes. To sum up, e-learning managers, instructors, and e-content designers should focus greater attention on the design of e-courses in order to motivate learners towards accepting them.

Even though the outcomes of this research are theoretically and empirically important since a significant improvement has been indicated in learner perceptions and intention towards e-learning acceptance, several limitations have to be highlighted. The research was carried out at one university and all students were from computer science field, so the findings cannot be generalised to the whole population in higher education. The other issue is that participants attended only one UDL-based inspired blended course. This may indicate their subjective perspective with regard to that individual course. Moreover, the experimental group is quite small and on the border of the minimum acceptable sample for such research. This may explain why the alpha values of five hypotheses were less than 0.1 and greater than 0.05. It is anticipated that recruiting a larger sample size can show better results. 
Finally, random assignment of participants to a condition can lead to avoiding any possible bias in the research findings. In order to address such limitations, further research is highly recommended.

\section{Conclusion}

In this study, a blended web design course was delivered using in-class sessions and e-learning system in which UDL principles were embraced. Then, UDL variables, namely, multiple means of representation, multiple means of action and expression, and multiple means of engagement were measured and integrated into TAM. The aim was to explore their influence on PU, PS, and ITU elearning. Overall, findings suggest that curricula design has a direct significant effect on learner perceptions. Furthermore, it seems that the UDL model is an effective pedagogical approach in promoting intentional behaviour for accepting e-learning. The comparison of learner perceptions and behavioural intention of those who attended a traditional-based blended learning (the control group) with those who attended the UDL-based blended learning (the experimental group) indicated that the latter had higher perceptions and willingness for adopting e-learning. This result should highly encourage e-learning managers, instructors, and practitioners to prioritise the design of e-courses in order to successfully implement e-learning.

The extended model explained an acceptable fit for e-learning usefulness, learner satisfaction, and usage intention. This was also clear from the comparison of the proposed model predictability with the original TAM. The results revealed a high improvement in the research framework. The qualitative analysis provided further support to the importance of a flexible e-courses design. Participants indicated that the use of several features and attributes in this blended e-learning course had the potential for promoting e-learning usefulness, reducing learning stress and effort, and enhancing the subject comprehension. On the other hand, other factors may need to be incorporated in order to improve the power of the proposed framework. Moreover, it is expected that our future research will recruit a larger sample size and integrate several UDL-based e-courses design in order to address the limitations of the present research. This can undoubtedly provide more support to the significant findings of this investigation.

\section{Acknowledgment}

The authors would like to thank the Iraqi Ministry of Higher Education and Scientific Research (MHESR-I) for supporting this study.

\section{References}

Ajzen, I. (1985). From intentions to actions: A theory of planned behavior. In J. Kuhl \& J. Beckmann (Eds.), Action control: From cognition to behavior (pp. 11-39). New York: Springer Verlag. doi:10.1007/978-3-642-69746-3_2

Ajzen, I., \& Fishbein, M. (1980). Understanding attitudes and predicting social behaviour. Prentice- 
Hall, Inc., Englewood Cliffs.

Al-Azawei, A., \& Lundqvist, K. (2015). Learner differences in perceived satisfaction of an online learning: An extension to the Technology Acceptance Model in an Arabic sample. Electronic Journal of E-Learning, 13(5), 408-426.

Al-Azawei, A., Parslow, P., \& Lundqvist, K. (2016). Barriers and opportunities of e-Learning implementation in Iraq: A case of public universities. International Review of Research in Open and Distributed Learning, 17(5), 126-146.

Al-Azawei, A., Serenelli, F., \& Lundqvist, K. (2016). Universal design for learning (UDL): A content analysis of peer-reviewed journal papers from 2012 to 2015. Journal of the Scholarship of Teaching and Learning, 16(3), 39-56. doi:10.14434/josotl.v16i3.19295

Alhadithi, A., Idurs, R., \& Elameer, A. (2010). Re-engineering Iraqi higher education with the eeducation solutions. Recent Researches in Education, 37-42. Retrieved from http://www.wseas.us/e-library/conferences/2011/Penang/EDU/EDU-05.pdf

Ali, G. E., \& Magalhaes, R. (2008). Barriers to implementing e-learning: A Kuwaiti case study. International Journal of Training and Development, 12(1), 36-54.

Al-Mushasha, N. F., \& Nassuora, A. B. (2012). Factors determining e-learning service quality in jordanian higher education environment. Journal of Applied Sciences, 12(14), 1474-1480. doi:10.3923/jas.2012.1474.1480

Atchariyachanvanich, K., Siripujaka, N., \& Jaiwong, N. (2014). What makes university students use cloud-based e-learning?: Case study of KMITL students. International Conference on Information Society (I-Society 2014), 112-116. London. doi:10.1109/i-Society.2014.7009022

Bagozzi, R. P. (2007). The lagacy of the Technology Acceptance Model and a proposal for a paradigm shift. Journal of the Association for Information Systems, 8(4), 244-254.

Balakrishnan, V., \& Gan, C. L. (2016). Students' learning styles and their effects on the use of social media technology for learning. Telematics and Informatics, 33(3), 808-821. doi:10.1016/j.tele.2015.12.004

Bandura, A. (1990). Perceived self-efficacy in the exercise of control over aids infection. Evaluation and Program Planning, 13(1), 9-17. doi:10.1016/0149-7189(90)90004-G

Barrio-García, S., Arquero, J. L., \& Romero-Frías, E. (2015). Personal learning environments acceptance model : The role of need for cognition, e-Learning satisfaction and students' perceptions. Educational Technology \& Society, 18(3), 129-141.

Basha, A. D., Mnaathr, S. H., Alkhayat, R. Y., \& Jamaludin, R. (2013). Importance apply of e-learning as an instructional design for new electronic environment in Iraqi universities. International Journal of Scientific \& Engineering Research, 4(6), 650-653.

Benbasat, I., \& Barki, H. (2007). Quo vadis, TAM? Journal of the Association for Information Systems, 8(4), 211-218. 
Benton-Borghi, B. H. (2013). A universally designed for learning (UDL) infused technological pedagogical content knowledge (TPACK) practitioners' model essential for teacher preparation in the 21st century. Journal of Educational Computing Research, 48(2), 245-265. doi:10.2190/EC.48.2.g

Bolliger, D. U., \& Wasilik, O. (2009). Factors influencing faculty satisfaction with online teaching and learning in higher education. Distance Education, 30(1), 103-116. doi:10.1080/01587910902845949

Bryans Bongey, S., Cizadlo, G., \& Kalnbach, L. (2010). Blended solutions using a supplemental online course site to deliver universal design for learning (UDL). Campus-Wide Information Systems, 27(1), 4-16. doi:10.1108/10650741011011246

Bühler, C., \& Fisseler, B. (2007, September 26 -28). Accessible e-learning and educational technologyExtending learning opportunities for people with disabilities. Conference ICL2007, 1-11. Retrieved from https://hal.archives-ouvertes.fr/hal-00257138/

Cassel, C., Hackl, P., \& Westlund, A. H. (1999). Robustness of partial least-squares method for estimating latent variable quality structures. Journal of Applied Statistics, 26(4), 435-446. doi:10.1080/02664769922322

CAST. (2011). Universal Design for Learning ( UDL ) guidelines version 2.o. Wakefeild, MA: Author. Retrived from http://www.udlresource.com/uploads/1/2/1/2/12126894/udl guidelines version 2.0 final 3. pdf

Center for Applied Special Technology. (2011). Universal design for learning ( UDL ) guidelines version 2.o. Wakefeild, MA: Author.

Center for Applied Special Technology. (2014). UDL Center [Blog post]. Retrieved from http://www.udlcenter.org/aboutudl/udltechnology

Center for Universal Design. (2015). Retrieved from http://www.ncsu.edu/ncsu/design/cud/about ud/about ud.htm

Cheng, G., \& Chau, J. (2014). Exploring the relationships between learning styles, online participation, learning achievement and course satisfaction: An empirical study of a blended learning. British Journal of Educational Technology, 47(2), 257-278. doi:10.1111/bjet.12243

Chiu, C. M., Hsu, M. H., Sun, S. Y., Lin, T. C., \& Sun, P. C. (2005). Usability, quality, value and elearning continuance decisions. Computers and Education, 45(4), 399-416. doi:10.1016/j.compedu.2004.06.001

Cigdem, H., \& Ozturk, M. (2016). Factors affecting students' behavioral intention to use LMS at a Turkish post-secondary vocational school. International Review of Research in Open and Distance Learning, 17(3), 276-295.

Conner, T. (2016). Relationships: The key to student engagement. International Journal of Education and Learning, 5(1), 13-22. doi:http://dx.doi.org/10.14257/ijel.2016.5.1.02 
Creswell, J. W., Klassen, L. A. C., Clark, V. L. P., \& Smith, L. K. C. (2011). Best practices for mixed methods research in the health sciences. National Institutes of Health, Office of Behavioral and Social Sciences Research. Retrieved from https://www.nursing.virginia.edu/media/Best_Practices_for_Mixed_Methods_Research.pdf

Dallas, B. K., Mccarthy, A. K., \& Long, G. (2016). Examining the educational benefits of and attitudes toward closed captioning among undergraduate students. Journal of the Scholarship of Teaching and Learning, 16(2), 56-65. doi:10.14434/josotl.v16i2.19267

Davies, P. L., Schelly, C. L., \& Spooner, C. L. (2012). Measuring the effectiveness of Universal Design for Learning intervention in postsecondary education. Journal of Postsecondary Education and Disability, 26(3), 195-220.

Davis, F. D. (1986). A technology acceptance model for empirically testing new end-user information systems: Theory and results. Doctorol thesis. Wayne State University, Detroit, Michigan, USA. Retrieved from http://dspace.mit.edu/handle/1721.1/15192

Davis, F. D., Bagozzi, R., \& Warshaw, P. R. (1989). User acceptance of computer technology: A comparison of two theoretical models. Management Science, 35(8), 982-1003.

Derouin, R. E., Fritzsche, B. A., \& Salas, E. (2005). E-learning in organizations. Journal of Management, 31(6), 920-940. doi:10.1177/0149206305279815

Elameer, A. S., \& Idrus, R. M. (2011). National e-learning strategy to enhance and enrich the Iraqi universities. US-China Education Review, ISSN 1548-6613, 4, 481-496.

Faqih, K. M. S. (2016). Which is more important in e-learning adoption, perceived value or perceived usefulness? Examining the moderating influence of perceived compatibility. In e-Proceeding of the 4th Global Summit on Education 2016 (pp. 372-398).

Fornell, C., \& Larcker, D. F. (1981). Evaluating structural equation models with unobservable variables and measurement error. Journal of Marketing Research (JMR). 18(1), 39-50. 12p. 1 Diagram. doi:10.2307/3151312

Graf, S. (2007). Adaptivity in learning management systems focussing on learning styles (Doctoral dissertation). Athabasca University, Canada.

Govindasamy, T. (2002). Successful implementation of e-learning: Pedagogical considerations. The Internet and Higher Education, 4(3), 287-299. doi:http://dx.doi.org/10.1016/S10967516(01)00071-9

Hair, J. F., Black, W. C., Babin, B. J., Anderson, R. E., \& Tatham, R. L. (2006). Multivariate data analysis (6 ${ }^{\text {th }}$ ed.). Upper Saddle River, NJ: Pearson Prentice Hall.

Hall, T. E., Cohen, N., Vue, G., \& Ganley, P. (2015). Addressing learning disabilities with UDL and technology: Strategic Reader. Learning Disability Quarterly, 38(2), 72-83.

doi:10.1177/0731948714544375

He, Y. (2014). Universal Design for Learning in an online teacher education course: Enhancing 
learners ' confidence to teach online. MERLOT Journal of Online Learning and Teaching, 1O(2), $283-298$.

Hwang, Y., Al-Arabiat, M., \& Shin, D.-H. (2015). Understanding technology acceptance in a mandatory environment: A literature review. Information Development, 31(3), 1-18. doi:10.1177/0266666915593621

Internet World Stats. (2015). Retrieved January 1, 2015 from http://www.internetworldstats.com/stats5.htm

Kannan, K., \& Narayanan, K. (2015). A Structural equation modelling approach for massive blended synchronous teacher training. Educational Technology \& Society, 18(3), 1-15.

Kumar, K. L., \& Wideman, M. (2014). Accessible by design: Applying UDL principles in a first year undergraduate course. Canadian Journal of Higher Education, 44(1), 125-147.

Lee, Y., Kozar, A. K., \& Larsen, K. R. T. (2003). The technology acceptance model: Past, present, and future. The Communications of the Association for Information Systems, 12(1), 752-780.

Leedy, P. D., \& Ormrod, J. E. (2005). Practical research: Planning and design (8th ed.). New Jersey, USA: Pearson: Merrill Prentice-Hall.

Liaw, S. S. (2008). Investigating students' perceived satisfaction, behavioral intention, and effectiveness of e-learning: A case study of the Blackboard system. Computers \& Education, 51(2), 864-873. doi:10.1016/j.compedu.2007.09.005

Liu, I. F., Chen, M. C., Sun, Y. S., Wible, D., \& Kuo, C. H. (2010). Extending the TAM model to explore the factors that affect Intention to use an online learning community. Computers and Education, 54(2), 600-610. doi:10.1016/j.compedu.2009.09.009

Lowry, P. B., \& Gaskin, J. (2014). Partial least squares (PLS) structural equation modeling (SEM) for building and testing behavioral causal theory: When to choose it and how to use it. IEEE Transactions on Professional Communication, 57(2), 123-146. doi:10.1109/TPC.2014.2312452

Mangiatordi, A., \& Serenelli, F. (2013). Universal design for learning: A meta-analytic review of 80 abstracts from peer reviewed journals. Research on Education and Media, 5(1), 109-118.

Matar, N., Hunaiti, Z., Halling, S., \& Matar, Š. (2010). E-Learning acceptance and challenges in the Arab region. In ICT Acceptance, Investment and Organization (pp. 184-200). doi:10.4018/9781-60960-048-8.cho13

Mayer, R. E. (2009). Multimedia learning (2 ${ }^{\text {nd }}$ ed.). New York: Cambridge University Press.

Moon, J., \& Kim, Y. (2001). Extending the TAM for a World-Wide Web context. Information \& Management, 38(4), 217-230.

Morra, T., \& Reynolds, J. (2010). Universal design for learning: Application for technology-enhanced learning. Inquiry: The Journal of the Virginia Community Colleges, 15(1), 43-51.

Ong, C. S., \& Lai, J. Y. (2006). Gender differences in perceptions and relationships among dominants 
of e-learning acceptance. Computers in Human Behavior, 22(5), 816-829.

doi:10.1016/j.chb.2004.03.006

Pallant, J. (2013). SPSS survival manual: A step by step guide to data analysis using IBM SPSS (5th ed.). Maidenhead: Open University Press.

Park, S. Y. (2009). An analysis of the Technology Acceptance Model in understanding university students' behavioral intention to use e-Learning. Educational Technology \& Society,12(3), 150162. doi: 10.1007/soo340-009-3513-0

Rao, K., Ok, M. W., \& Bryant, B. R. (2014). A review of research on Universal Design Educational models. Remedial and Special Education, 35(3), 153-166. doi:10.1177/0741932513518980

Rienties, B., \& Toetenel, L. (2016). The impact of learning design on student behaviour, satisfaction and performance: A cross-institutional comparison across 151 modules. Computers in Human Behavior, 6o, 333-341. doi:10.1016/j.chb.2016.02.074

Rose, D. H., \& Meyer, A. (2002). Teaching every student in the digital age: Universal design for learning. Alexandria, VA: ASCD.

Rose, D. H., \& Strangman, N. (2007). Universal design for learning: Meeting the challenge of individual learning differences through a neurocognitive perspective. Universal Access in the Information Society, 5(4), 381-391. doi:10.1007/s10209-006-0062-8

Rose, D., Harbour, W., Johnston, C. S., Daley, S., \& Abarbanell, L. (2006). Universal design for learning in postsecondary education. Journal of Postsecondary Education and Disability, 19(2), $1-27$.

Rovai, A. P. (2004). A constructivist approach to online college learning. Internet and Higher Education, 7(2), 79-93. doi:10.1016/j.iheduc.2003.10.002

Sagor, R. (2000). Guiding school improvement with action research. Alexandria, VA: Association for Supervision and Curriculum Development.

Said, H., Kirgis, L., Verkamp, B., \& Johnson, L. (2015). On-line vs . face-to-face delivery of information technology courses: Students' assessment. Journal of Information Technology Education: Research, 14, 297-312.

Seale, J., \& Cooper, M. (2010). E-learning and accessibility: An exploration of the potential role of generic pedagogical tools. Computers and Education, 54(4), 1107-1116. doi:10.1016/j.compedu.2009.10.017

Shin, W. S., \& Kang, M. (2015). The use of a mobile learning management system at an online university and its effect on learning satisfaction and achievement. International Review of Research in Open and Distributed Learning, 16(3), 110-130.

Smith, F. G. (2012). Analyzing a college course that adheres to the Universal Design for Learning (UDL) framework. Journal of the Scholarship of Teaching and Learning, 12(3), 31-61. 
Smith, S. J., \& Harvey, E. E. (2014). K-12 online lesson alignment to the principles of Universal Design for Learning: The Khan Academy. Open Learning: The Journal of Open, Distance and ELearning, 29(3), 222-242. doi:10.1080/02680513.2014.992402

Sniehotta, F. F., Scholz, U., \& Schwarzer, R. (2005). Bridging the intention-behaviour gap: Planning, self-efficacy, and action control in the adoption and maintenance of physical exercise. Psychology \& Health, 2O(2), 143-160. doi:10.1080/08870440512331317670

Šumak, B., Heric ``ko, M., \& Pušnik, M. (2011). A meta-analysis of e-learning technology acceptance: The role of user types and e-learning technology types. Computers in Human Behavior, 27(6), 2067-2077. doi:10.1016/j.chb.2011.08.005

Sun, P. C., Tsai, R. J., Finger, G., Chen, Y. Y., \& Yeh, D. (2008). What drives a successful e-Learning? An empirical investigation of the critical factors influencing learner satisfaction. Computers \& Education, 5o(4), 1183-1202. doi:10.1016/j.compedu.2006.11.007

Tarhini, A., Hone, K., \& Liu, X. (2015). A cross-cultural examination of the impact of social, organisational and individual factors on educational technology acceptance between British and Lebanese university students. British Journal of Educational Technology, 46(4), 739-755. doi:10.1111/bjet.12169

Tarus, J. K., Gichoya, D., \& Muumbo, A. (2015). Challenges of implementing e-learning in Kenya : A case of Kenyan public universities. International Review of Research in Open and Distributed Learning, 16(1), 120-141.

Taylor, S., \& Todd, P. A. (1995). Understanding information technology usage: A test of competing models. Information Systems Research, 6(2), 144-176. doi:10.1287/isre.6.2.144

Teng, K. E. (2015). An analysis of ODL student perception and adoption behavior using the Technology Acceptance Model. The International Review of Research in Open and Distributed Learning, 15(6), 275-288.

Venkatesh, V., \& Bala, H. (2008). Technology Acceptance Model 3 and a research agenda on interventions. Decision Sciences, 39(2), 273-315. doi:10.1111/j.1540-5915.2008.00192.x

Venkatesh, V., \& Davis. (2000). A theoretical extension of the Technology Acceptance Model: Four longitudinal field studies. Management Science, 46(2), 186-204. doi:10.1287/mnsc.46.2.186.11926

Venkatesh, V., Morris, M. G., Davis, G. B., \& Davis, F. D. (2003). User acceptance of information technology: Toward a unified view. MIS Quarterly, 27(3), 425-478. doi:10.2307/30036540

Weng, C., \& Tsai, C. (2015). Social support as a neglected e-learning motivator affecting trainee's decisions of continuous intentions of usage. Australasian Journal of Educational Technology, 31(2), 177-192.

Wixom, B. H., \& Todd, P. A. (2005). A theoretical integration of user satisfaction and technology acceptance. Information Systems Research, 16(1), 85-102. doi:10.1287/isre.1050.0042 
Wu, J. H., Tennyson, R. D., \& Hsia, T. L. (2010). A study of student satisfaction in a blended elearning system environment. Computers \& Education, 55(1), 155-164.

doi:10.1016/j.compedu.2009.12.012

Yi, M. Y., \& Hwang, Y. (2003). Predicting the use of web-based information systems: Self-efficacy, enjoyment, learning goal orientation, and the technology acceptance model. International Journal of Human Computer Studies, 59(4), 431-449. doi:10.1016/S1071-5819(03)oo114-9

Zogheib, B., Rabaa, A., Zogheib, S., \& Elsaheli, A. (2015). University student perceptions of technology use in mathematics learning. Journal of Information Technology Education: Research, 14, 417438.

Athabasca

University

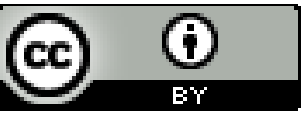

